OECDpublishing

ASSIGNING

RESPONSIBILITIES ACROSS

LEVELS OF GOVERNMENT

\title{
DOROTHÉE ALLAIN-DUPRÉ
}

OECD WORKING PAPERS

\section{ON FISCAL FEDERALISM}

September 2018 No. 24 


\title{
OECD NETWORK ON FISCAL RELATIONS ACROSS LEVELS OF GOVERNMENT (THE “FISCAL NETWORK”)
}

\author{
FISCAL FEDERALISM WORKING PAPER SERIES
}

This series is designed to make available to a wider readership selected studies drawing on the work of the OECD's Network on Fiscal Relations across Levels of Government. Authorship is usually collective, but principal writers are named. The papers are generally available only in their original language (English or French) with a short summary available in the other.

OECD Working Papers should not be reported as representing the official views of the OECD or of its member countries. The opinions expressed and arguments employed are those of the author(s).

Working Papers describe preliminary results or research in progress by the author(s) and are published to stimulate discussion on a broad range of issues on which the OECD works. Comments on Working Papers are welcomed, and may be sent to the OECD Network on Fiscal Relations, 2 rue André-Pascal, 75775 Paris Cedex 16, France. This working paper has been authorised for release by the Director of the Centre for SMEs, Entrepreneurship, Regions and Cities, Lamia Kamal-Chaoui.

This document and any map included herein are without prejudice to the status of or sovereignty over any territory, to the delimitation of international frontiers and boundaries and to the name of any territory, city or area.

The statistical data for Israel are supplied by and under the responsibility of the relevant Israeli authorities. The use of such data by the OECD is without prejudice to the status of the Golan Heights, East Jerusalem and Israeli settlements in the West Bank under the terms of international law.

Comments on the series are welcome, and should be sent to either fiscalnetwork@oecd.org or the OECD Network on Fiscal Relations, 2 rue André Pascal, 75775 PARIS CEDEX 16, France.

You can copy, download or print OECD content for your own use, and you can include excerpts from OECD publications, databases and multimedia products in your own documents, presentations, blogs, websites and teaching materials, provided that suitable acknowledgement of OECD as source and copyright owner is given. All requests for public or commercial use and translation rights should be submitted to rights@oecd.org.

Copyright OECD 2018. 
Abstract

The past decades have seen an undeniable trend towards decentralisation and greater diversity of multilevel governance arrangements around the world. Decentralisation outcomes depend on the way decentralisation is designed and implemented. A key issue for the effectiveness of decentralisation is linked to the way responsibilities are assigned across levels of government. The literature on fiscal federalism has provided some general guidelines that provide a point of departure for thinking about the assignment of responsibilities. However, when looking at country practices, the difference between theory and country experience appears to be significant. This paper reviews the trends, challenges and good practices in the way responsibilities are distributed across levels of government. It concludes with a set of guidelines for policy-makers, to better assign responsibilities across levels of government for more effective decentralisation.

Keywords: Public economics, intergovernmental relations, governance, regional economics

JEL classification: $H 7$

\section{Résumé}

Au cours des dernières décennies, il y a eu une tendance indéniable à la décentralisation et à une diversité plus grande des systèmes de gouvernance pluri-niveaux dans le monde. Les résultats de la décentralisation dépendent largement de la manière dont elle est conçue et mise en œuvre. Un enjeu clef est lié à la manière dont les responsabilités sont assignées entre niveaux de gouvernement. La littérature sur le fédéralisme fiscal a donné des principes clefs sur cette question de l'allocation des responsabilités. Cependant, lorsque l'on examine l'expérience des pays, on observe une différence de taille entre la théorie et la pratique. Ce papier analyse les tendances, défis et bonnes pratiques dans la manière dont les responsabilités sont assignées entre niveaux de gouvernement. Il conclut par une série de lignes directrices pour mieux allouer les responsabilités entre niveaux de gouvernement, pour une décentralisation plus effective.

Mots clefs: Economie publique, relations intergouvernementales, gouvernance, économie régionale

Classification JEL: H7 


\title{
Assigning responsibilities across levels of government: Trends, challenges and guidelines for policy-makers
}

\author{
By Dorothée Allain-Dupré ${ }^{1}$
}

\section{Introduction}

The past decades have seen an undeniable trend towards decentralisation and greater diversity of multilevel governance arrangements around the world (Hooghe et al., 2016; OECD/UCLG, 2016h). It has been called the "silent revolution" (Ivanyna and Shah, 2014).

Decentralisation is not good or bad in itself. Its outcomes much depend on the way the process is designed and implemented, on adequate subnational capacity, and on the quality of multi-level governance. When it is properly conducted and balanced across policy areas, there is evidence that decentralisation may be conducive to growth (OECD, 2016a; Shah 2007, Ivanyna and Shah, 2014). Beyond economic benefits, decentralisation might allow enhanced accountability, transparency and citizens' engagement, thus improving democracy.

A key issue in the effectiveness of decentralisation is linked to the way responsibilities are assigned across levels of government. The literature on fiscal federalism has provided some general guidelines that provide a point of departure for thinking about the assignment of responsibilities. However, when looking at country practices, the difference between theory and country experience appears to be significant, in both developing and developed countries. It is thus critical to learn from country experience on what are the main trends, challenges and good practices that can allow peer-learning and improvements in multi-level governance systems. What trends can be observed in the way political, administrative, and fiscal responsibilities are distributed across subnational governments? How do countries manage shared responsibilities? How have asymmetric arrangements affected multilevel governance?

This paper explores these questions. It relies on multiple empirical sources on multilevel governance. The paper uses OECD data on subnational finance and investment (OECD, 2017; OECD/UCLG, 2016h) and the Fiscal Decentralisation Database. The paper also uses data from the Regional Authority Index, which provides comprehensive measures of

\footnotetext{
${ }^{1}$ The paper was written by Dorothée Allain-Dupré. The author is grateful to Sandra Chapman Osterkatz, from the University of North Carolina (UNC) at Chapel Hill and Dr Anwar Shah, Brookings Institution, Washington, DC for their substantial inputs and comments on the draft. The author is also grateful to Rudiger Ahrend, Bert Brys, David Bradbury, Isabelle Chatry, Sean Dougherty, Michele Harding, Varinia Michalun, Joaquim Oliveira Martins and Isidora Zapata from the OECD Secretariat for their useful comments. The paper builds upon the work conducted on multi-level governance by the OECD Regional Development Policy Committee, as well as work produced by the OECD Network on Fiscal Relations across Levels of Government. The author is grateful to Delegates of the Fiscal Network and the Regional Development Policy Committee for their comments, during the sessions in which the paper was discussed (24 November 2017 for the Fiscal Network and 8 December 2017 for the RDPC).
} 
decentralisation for 81 countries (Hooghe et al., 2016), as well as data on the Local Autonomy Index which provide similar measurement at the municipal level. For a detailed assessment of country practices, the paper focuses on the Territorial Reviews and Multi-level Governance Reviews conducted since 2005 by the Regional Development Policy Committee of the OECD ${ }^{2}$. The analysis is complemented with findings from the Economic Surveys of the past decade and from the 2016 synthesis on the topic (OECD, 2016b). Other recent reports are used, notably OECD (2017), on multi-level governance reforms in OECD countries, as well as work linked to the implementation of the OECD Recommendation on Effective Public Investment across Levels of Government.

The structure of the paper is as follows: the first section presents the main findings of the paper. The second section highlights the trends in the way responsibilities are distributed across countries. The third section focuses on the challenges that countries face which are largely shared by most countries, the good practices and reforms that have been put in place to address these challenges and improve the functioning of multi-level governance, as well as the lessons that can be learned from country experience. The final section concludes with a set of guiding principles for policy-makers, to better assign responsibilities across levels of government for more effective decentralisation.

\section{Main findings}

The main findings of the paper are presented below:

\section{Trends}

- Over the past seventy years, the overall trend has been in favour of greater decentralisation. Decentralisation trends are seen in most regions of the world (Hooghe et al., 2016): Western countries since the 1960s/1970s (mostly European countries); more recently, Asia and Pacific since the 1980s; and Latin America since the 1990s. Exceptions to this global trend are the Middle East and the North Africa region. Two trends in decentralisation stand out: the reinforcement of local autonomy (municipal authority) (Ladner, Keuffer and Baldersheim, 2015; Ivanyna and Shah, 2014) and the strengthening of regions with countries either creating new regions or strengthening existing ones (regionalisation). Of the 81 countries covered by the Regional Authority Index, 52 experienced a net increase in the power of regions and only nine experienced a net decline (Hooghe et al., 2016).

- Changes in the spending shares of certain functions do not necessarily imply a change in effective responsibility. Fiscal indicators can be misleading because so-called "decentralised" expenditure can be just in reality "deconcentrated" or "delegated" expenditure made on behalf of the central government. It is thus critical to go beyond fiscal indicators when measuring decentralisation and multi-level governance systems. The Regional Authority Index (Hooghe et al., 2016, 2010) provides a comprehensive measure of regions' degree of "power" of regional authority, in a similar way that the Fiscal Network’s Tax Autonomy indicators have for revenue authority.

- Studies now indicate that a country's overall territorial size matters more than the level of GDP per capita in determining the scope of regional authority (Hooghe and Marks,

${ }^{2}$ From 2005 to 2015 the Regional Development Policy Committee conducted more than 20 Territorial Reviews at the national level. Annex A includes a summary of the countries for which the OECD has performed these Territorial Reviews at the national level, focusing on issues linked to assignment of responsibilities across levels of government. 
2016), even though there is a positive correlation between the level of GDP per capita and the degree of decentralisation (OECD/UCLG, 2016h).

- Although differences between unitary and federal countries have been diminishing over the past fifty years, some specificities remain for federal countries, like the constitutional arrangements concerning shared sovereignty. In unitary countries there is a tremendous variation in arrangements, and this variation has grown in the past fifty years. Countries can be grouped into four families based on their degree of decentralised spending and tax autonomy, characteristics which cut across federal versus unitary distinctions.

- It is rare for competences to be truly exclusive. Most responsibilities are shared across levels of government, in particular between the municipal and regional levels. In practice, the question is not of a clear-cut allocation of responsibilities, but rather of how to manage shared functions and responsibilities.

- Assessing a generalised ideal territorial allocation of a given competence, and whether it should be shared or not, is by definition impossible because the conditions in each country and region are distinct and the way responsibilities are assigned depends on the geography, size of the country, history, institutions, culture and capacity - which differ greatly across countries. However, some trends are common to all countries in the way responsibilities are assigned across local and intermediary levels of government: there is greater variation across countries in the distribution of competences at the regional level, and less variation at the local level.

- A major trend in recent decades has been asymmetric (or differentiated) decentralisation. This means that SNGs have varying degrees of responsibility, depending on their capacity, population (urban or metropolitan areas), certain characteristics like geographic characteristics (islands for example). This is not a new trend, but this has accelerated in recent decades - in particular for metropolitan governance.

\section{Challenges, good practices and lessons}

OECD Reviews show that countries share similar challenges: (i) unclear assignment of responsibilities; (ii) resources and capabilities bottlenecks and (iii) co-ordination challenges, both vertically and horizontally, and scale issues for public investment and service delivery. This is consistent with the challenges reported in the academic literature on the topic (Shah, 2014; Rodriguez-Posé 2008). Overall, most of the challenges related to multilevel governance faced by these countries are not intrinsic to the level of decentralisation but rather to how the multilevel governance relationships are managed.

\section{Unclear assignment}

- The lack of clarity in the assignment was raised in most Territorial Reviews and Economic Surveys as among the largest challenges in multi-level governance. Such unclear assignment poses a number of problems that constitute major obstacles in ensuring overall efficiency and local political accountability.

- The problem is not only that policy areas are poorly defined, it also comes from the fact that functional responsibilities - i.e. financing, regulating, monitoring - within each policy area - are often not clearly defined, or not consistent. Such unclear allocation of responsibilities and functions is particularly notable for policy areas which are the most 'shared' across levels of government, in particular infrastructure (transport), education, spatial planning, health or labour market policy. Most of the countries that have fairly clear delineation of responsibilities and functions today did not start out that way, but have realised the importance of such reforms and addressed them over time. 
- The way responsibilities should be assigned within each policy area is context specific, however, some common principles - in terms of scale and economies of scope - apply in all contexts. For example, issues such as regional roads, regional economic development, and higher education are often managed at the regional level in OECD countries, as these topics require by definition a certain scale to focus on urban-rural linkages.

- Neither Territorial Reviews nor Economic Surveys recommend shifting more responsibilities to lower levels of government. Only in a few cases do the reviews suggest this kind of shift. Most Economic Surveys also avoid mentioning the level to which a certain function or policy area should be assigned (OECD, 2016b). However, some broad recommendations can be made in the policy areas of infrastructure education, health or land use, for example, on how to manage these shared responsibilities.

\section{Resources and capabilities bottlenecks}

- A lack of clarity in assignment does not allow for guidance in the assignment of revenues: for example, what type of revenues for what type of responsibilities.

- One of the most frequent challenges is the misalignment of responsibilities allocated to subnational governments with the resources available to them.

- Another challenge is the lack of sufficient fiscal autonomy at the subnational level. In some countries, transfers to SNGs are almost entirely earmarked by central government, thus limiting strongly the subnational fiscal autonomy and the ability to tailor policy answers to local needs. The situation is worsened when the allocation of transfers is unstable, unpredictable, or not transparent. In many countries, subnational governments may also have taxing powers they do not use or underutilise.

- Beyond the fiscal capacity issues, reviews repeatedly report the lack of adequate capacities - in terms of staff, expertise, scale - to address complex issues such as strategic planning, procurement, infrastructure investment, oversight in local public service delivery, performance monitoring, etc. Institutional capacities of SNGs vary enormously within countries, for all countries surveyed, even most developed countries (Rodriguez-Posé et al 2012; OECD/CoR, 2015c).

- In many countries, all SNGs regardless of size are responsible for delivering the same set of public services. The lack of flexibility to adapt the organisational structure of municipalities to local characteristics and demands hinders capacity building at the local level.

- An increasing number of countries are using differentiated/asymmetric approaches when assigning responsibilities, based on population size, rural/urban classification and fiscal capacity criteria. Asymmetric arrangements can entail the possibility to delegate some tasks to a higher level of government through ad hoc agreements for a given period.

- For the central government to be able to provide support, the right diagnosis of the different challenges needs to be in place. Territorial Reviews highlight that monitoring and data collection are often lacking, and few countries have rigorous systems for evaluating subnational capacity needs. 
Co-ordination challenges and scale issues

- The lack of co-ordination across jurisdictions is also a key challenge, mentioned by a majority of Territorial Reviews. Often, subnational governments are too small to deliver public services or invest at the relevant scale.

- Another common finding is that of co-ordination challenges across the national and subnational governments.

\section{Lessons}

- The paper concludes with 10 guidelines for effective assignment of responsibilities, based on practical experience. They are set out below (Box 1). 


\section{Box 1. Ten guidelines for effective assignment of responsibilities to make decentralisation work}

1) Clarify the sector responsibilities assigned to different government levels: while inevitably most responsibilities are shared across levels of government, it is crucial to ensure adequate clarity and mutual understanding of the role of each level of government in the different policy areas to avoid duplication, waste, and loss of accountability.

2) Clarify the functions assigned to different government levels: equally important than the clarity in the assignment of policy areas, is the clarity in the different functions that are assigned - financing, regulating, strategic planning, implementing, or monitoring.

3) Ensure balance in the way different responsibilities and functions are decentralised: balanced decentralisation - i.e. when the various policy functions are decentralised to a similar extent - is conducive to growth (OECD 2016b). Ensuring balance in the way various policy functions are decentralised is essential to allow for complementarities across policies and integrated policy packages for effective territorial development approaches (OECD, 2014).

4) Align responsibilities and revenues and enhance capacity of subnational governments to manage their resources : the allocation of resources should be matched to the assignment of responsibilities assigned to subnational governments (SNGs). SNGs should control a portion of subnational resources in order to promote their accountability.

5) Actively support subnational capacity-building from the central government, on the human, institutional and strategic dimensions of subnational governments. More responsibilities at the subnational level need to be complemented with the human resources capable of managing them, and too often this dimension is under-estimated. Capacity development at the subnational level, particularly in poor or very small municipalities, must be actively supported with resources from the centre, and require long-term commitment.

6) Build adequate co-ordination mechanisms across levels of government: since most responsibilities are shared, it is crucial to establish governance mechanisms to manage those joint responsibilities. Such tools for vertical co-ordination include for example platforms of dialogue, fiscal councils, contractual arrangements, conditionalities, standing commissions and intergovernmental consultation boards.

7) Support cross-jurisdictional co-operation through specific organisational arrangements or financial incentives, to increase efficiency through economies of scale in investment or public service delivery.

8) Allow for asymmetric arrangements and pilot experiences: Allow the possibility for asymmetric decentralisation, in which differentiated sets of responsibilities are given to different types of regions/cities, based on population size, urban/rural classification or fiscal capacity criteria. Ensure flexibility in implementation, allowing for pilot experiences in specific places/regions - and permanent adjustments through learning-by-doing.

9) Effective decentralisation requires complementary reforms in the governance of land-use, citizen participation and innovative public service delivery and governance.

10) Enhance data collection and strengthen performance monitoring: monitoring and data collection need to be carried out to monitor the effectiveness of subnational public service delivery and investments. Monitoring systems need to be designed as a way to provide useful data for decision-making and peer-learning and with a limited number of indicators. 


\section{Trends in the way responsibilities are distributed}

Looking at the way the various responsibilities are assigned at different levels of government is much more complex than one might think, because most responsibilities are shared across levels of government. A combination of indicators need to be taken into account to be able to assess the real power of the different levels of government, as fiscal indicators can be misleading - as they in general tend to over-estimate the real degree of decentralisation. They are useful to get a preliminary understanding of the situation and they facilitate international comparisons - but they need to be complemented with other indicators to understand the real degree of "authority" of subnational governments.

Fiscal matters are one dimension of multilevel governance, and several measures exist that address other dimensions as well. ${ }^{3}$ The Regional Authority Index (RAI) is a comprehensive attempt to measure the real degree of power of intermediate governments - beyond fiscal indicators (Box 2). The RAI takes the region as the unit of analysis and covers 81 countries along 10 dimensions annually from 1950-2010 (Hooghe, Marks and Schakel, 2010; Hooghe et al., 2016). The RAI distinguishes between tiers of intermediate governance. ${ }^{4}$ The 10 dimensions of the RAI include notably fiscal autonomy, borrowing autonomy, but also law making, executive control. The European Commission has used the same methodology to develop a Local Authority Index - at the municipal level (LAI). The LAI was developed for 39 EU countries and reports changes between 1990 and 2014.

\section{Box 2. Regional Authority Index}

The Regional Authority Index (RAI) tracks regional authority on an annual basis from 1950 to 2010 in 81 countries. The sample consists of all EU member states, all OECD member states, all Latin American countries, ten countries in Europe beyond the EU and eleven in the Pacific and South-East Asia. The unit of analysis is the individual region/ regional tier. The dataset encompasses subnational government levels with an average population of 150,000 or more. Regions with a special autonomous statute or asymmetrical arrangements are also coded separately.

Regional authority is measured along ten dimensions: institutional depth, policy scope, fiscal autonomy, borrowing autonomy, representation, law making, executive control, fiscal control, borrowing control, and constitutional reform.

Primary sources (constitutions, legislation) are triangulated with secondary literature and consultation of country experts to achieve reliable and valid estimates. A regional data set contains annual scores for regional governments or tiers and a country data set aggregates these scores to the country level.

Source: Hooghe et al (2016), Regional Authority Index (http://garymarks.web.unc.edu/data/regional-authority/).

\footnotetext{
3 Ivanyna and Shah (2014); Arzaghi and Henderson's index of institutional decentralization (2005); Brancati's levels of political decentralization (2008); Lijphart's federalism index (1999); Treisman's decision making decentralization (2002); Woldendorp, Keman, and Budge’s autonomy index (2000)

${ }^{4}$ Except in the case of special capital districts that fall at the regional level, the RAI does not code municipal governance. It also does not make assessments of what territorial units are doing with their authority, but focuses on formal multilevel governance arrangements.
} 
Ivanyna and Shah have also developed comprehensive measures of the degree of decision-making at the local level, i.e. the level of government closest to the people (Ivanyna and Shah, 2014). The dataset developed by Ivanyna and Shah covers 182 countries, and it captures institutional dimensions of political, fiscal and administrative autonomy enjoyed by local governments. These dimensions are then aggregated to develop a "decentralization index" and are then adjusted for heterogeneity to develop a "government closeness index". The analysis conducted on the basis of the index shows that decentralized local governance as measured by Government Closeness Index is associated with higher human development, lower corruption, and higher growth.

\section{Increased decentralisation}

Over the past seventy years, the overall trend around the world has been in favour of greater decentralisation. It is sometimes called the "silent revolution" (Ivanyna and Shah, 2014). Two trends in decentralisation standout: the reinforcement of local autonomy (municipal authority), and the strengthening of regions with countries either creating new regions or strengthen existing ones (regionalisation).

Of the 81 countries covered by the Regional Authority Index, 52 experienced a net increase in the degree of regional authority and only nine experienced a net decline ${ }^{5}$ (Hooghe et al., 2016) (Figure 1). Several countries have created new regions - notably in eastern European countries in the context of the EU enlargement. Others have strengthened existing regions: this is notably the case of recent or current reforms in Nordic countries, France or Italy. In several Nordic and Central and Eastern European countries, higher education, specialised health care or regional public transportation was reassigned from both the municipal and the central government level to a newly created regional level.

Figure 1. Increase in regional authority (RAI) since the 1950s

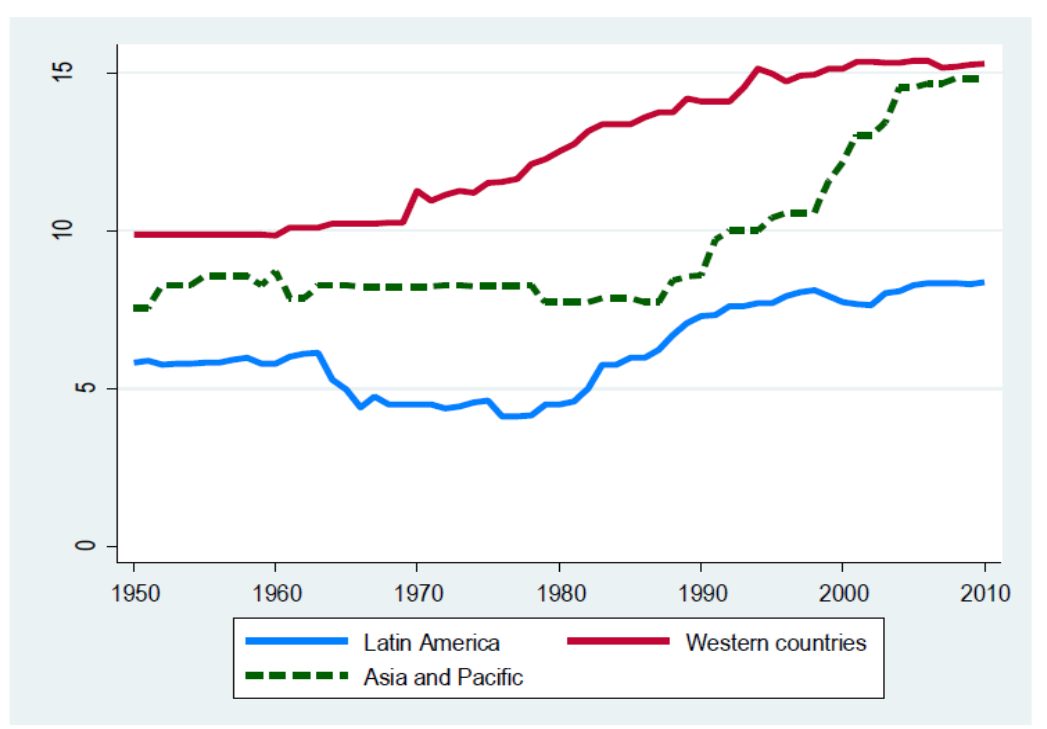

Source: Hooghe et al. (2016)

\footnotetext{
${ }^{5}$ For the 48 countries in the RAI dataset for the full sixty years, regional authority increased from an average of 8.1 to 12.6 .
} 
All regions of the world are concerned by the increase in the RAI: Western countries since 1960s/1970s (mostly European countries); more recently, Asia and Pacific since 1980s; and to a lesser extent Latin America since 1980s (Hooghe et al., 2016). Average regional authority was 55\% higher in 2010 than in 1950 (Hooghe, et al 2016; 45).

Studies are indicating that it is a country's territorial size (surface) that appears to matter more for the degree of regional authority than GDP per capita (Hooghe et al., 2016). Large countries tend to have more layers of autonomous intermediate government, which increases the level of regional authority vis-a-vis the centre. (OECD/UCLG, 2016h). However, the same observation is not valid when decentralisation is measured by the degree of autonomy of local governments, i.e. the closest level to citizens (Shah, 2014).

The same trend appears at the local/municipal level (Ivanyna and Shah, 2014). In Europe, the Local Autonomy Index" (LAI) shows an increase of local autonomy between 1990 and 2005 (Figure 2), especially in the new Central and Eastern European countries (Ladner, Keuffer, and Harald Baldersheim, 2015).

Figure 1. Local autonomy index: self-rule of local government in Europe

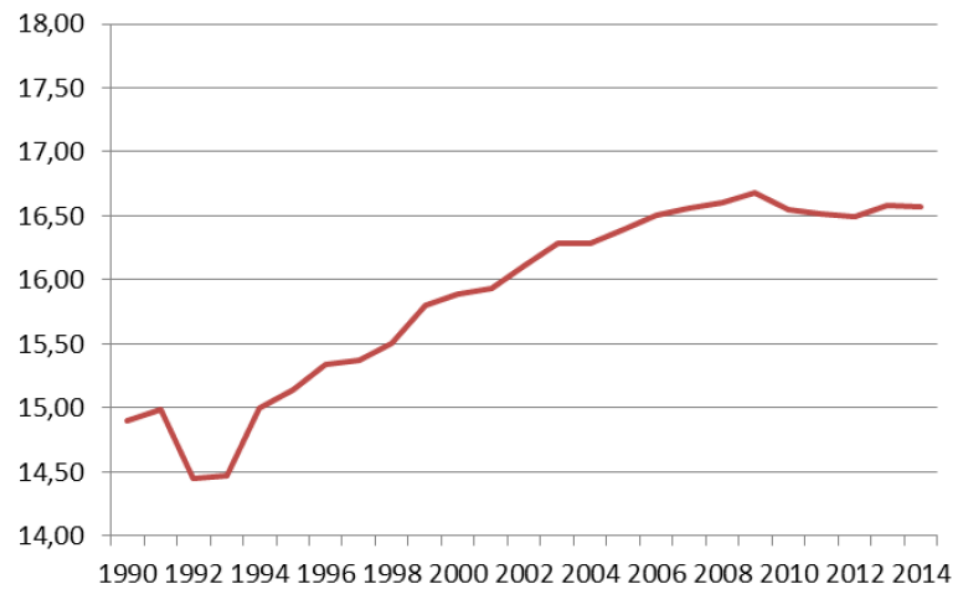

Note: Self-rule is measured as the sum of the eight variables that compose the Local Authority Index (see: http://ec.europa.eu/regional_policy/sources/docgener/studies/pdf/self_rule_index_en.pdf) Source: Ladner, Keuffer and Baldersheim (2015).

Decentralisation reforms have been implemented for a wide variety of reasons. According to Ivanah and Shah, "hugely complex factors such as political transition in Eastern Europe, the end of colonialism, the globalization and information revolution, assertion of basic rights of citizens by courts, divisive politics and citizens' dissatisfaction with governance and their quest for responsive and accountable governance have been some of the contributing factors in gathering this storm" (Ivanyna and Shah, 2014). As Hooghe and Marks (2016) point out, this is the result of unravelling the excessive centralisation brought about by authoritarianism, nationalist state building, and wars over the course of the late 20th century. Decentralisation has also been implemented as part of state reforms to improve efficiency and quality of public services, to enhance regional and local productivity and growth, to meet fiscal consolidation objectives in the aftermath of the recent economic crisis, or in response to the institutional programs of supranational organisations. Sometimes the motivations are not positive, as a number of countries have 
decentralized expenditures to shift deficit downwards. Historically, highly decentralised states were often the result of compromises required in countries with a diverse population, in part to ensure political stability.

\section{Four types of countries}

To get a first sense of the way responsibilities are assigned across levels of government in the OECD, it is useful to see what fiscal indicators say in terms of subnational expenditures in the different policy areas. In general in the OECD, subnational governments are key economic and policy actors: they are in charge of around $40 \%$ of public expenditures on average (with huge variations from $9 \%$ in Greece to almost $80 \%$ in Canada), of $63 \%$ of staff expenditures, $59 \%$ of public investment and $32 \%$ of tax revenues $^{6}$ - with variations from 3.5\% in Estonia to more than 50\% in Canada (Figure 3).

Figure 2. SNGs are key economic and policy actors across the OECD (2016)

\% of general government - 2016

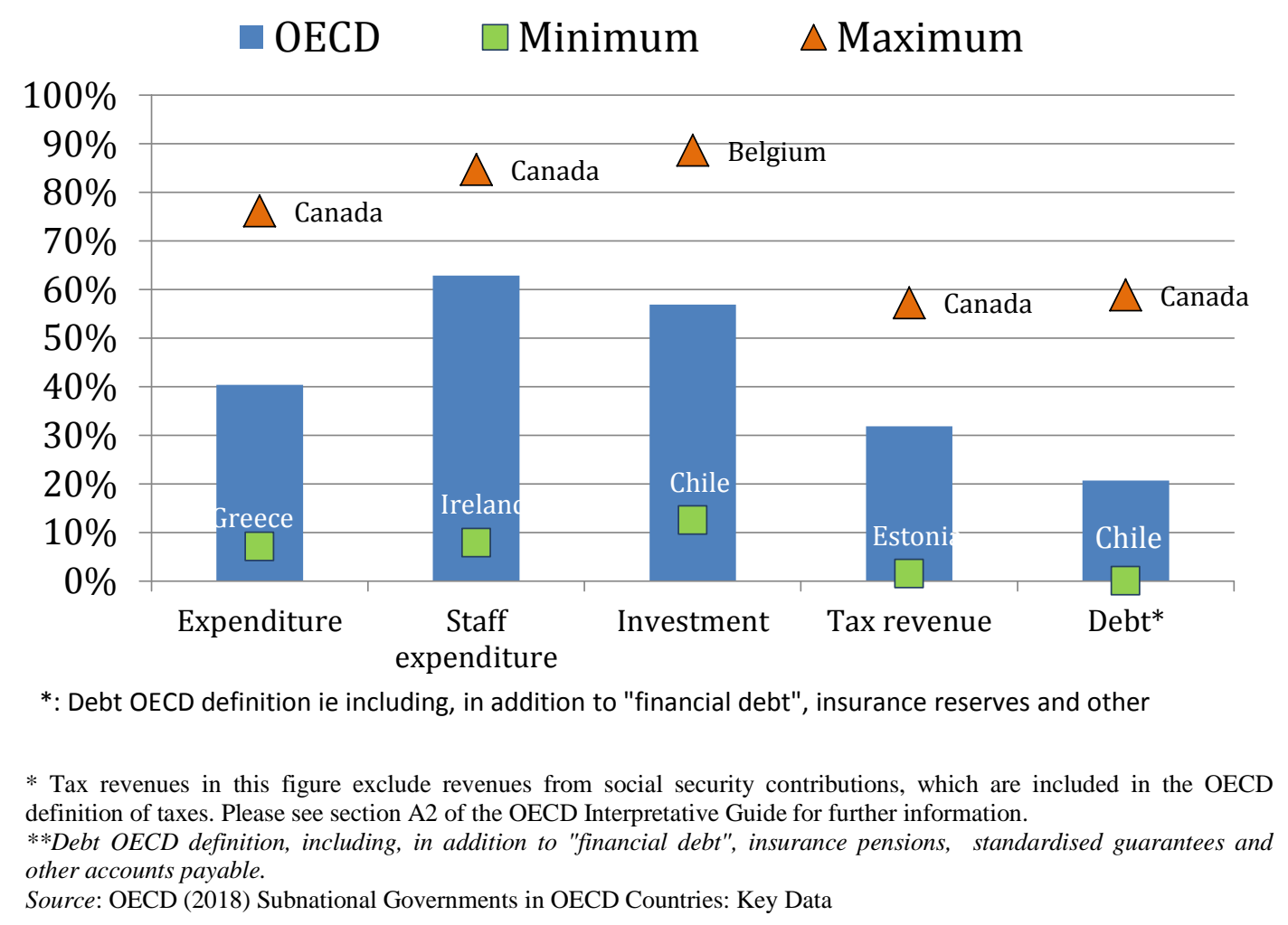

OECD countries have different levels of decentralisation measured by either the degree of spending decentralisation or by the tax revenues perceived by subnational governments (Figure 4). Across the OECD, tax revenues represent $44.6 \%$ of subnational government revenues. Transfers have slightly increased their share over the last two decades (OECD, 2016a). They now represent 37.2\% of subnational government revenues (OECD, 2018). In addition:

\footnotetext{
${ }^{6}$ excluding social contributions
} 
o Countries with the highest subnational government expenditure as a percentage of GDP are Australia, Belgium, Canada, Denmark, Finland, Germany, Japan, Spain, United States, Sweden, Switzerland;

o The structure of subnational government revenue varies also greatly across countries (Figure 5). Countries with the highest level of taxes (excluding social contributions) in their subnational revenues include for instance Canada, Denmark, Finland, Germany, Iceland, Japan, Switzerland, Spain, Sweden, and the United States ${ }^{7}$. The share of tax revenue is not an indication of tax autonomy, which depends on many factors - such as the right to introduce or to abolish a tax, to set tax rates, to define the tax base, or to grant tax allowances or reliefs to individuals and firms (see Box 2).

\section{Figure 3. Subnational government expenditure as a percentage of GDP and total public} expenditure (2016)

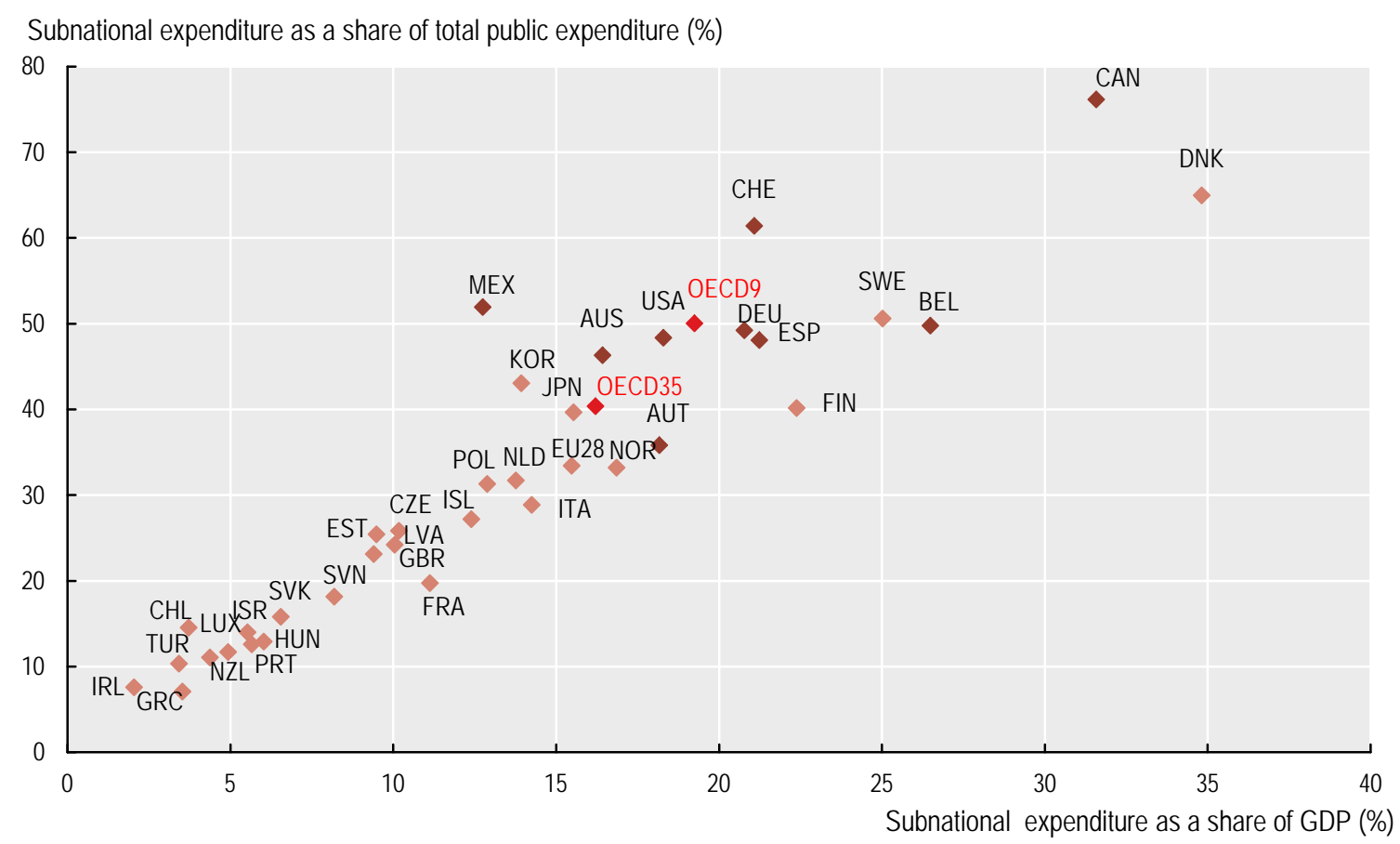

Source: OECD (2018), Subnational Governments in OECD Countries: Key Data.

${ }^{7}$ From 1995 to 2011, tax autonomy increased, at the expense of tax-sharing systems (OECD, 2016). 
Figure 4. The structure of subnational government revenue varies greatly across countries $(\%, 2016)$

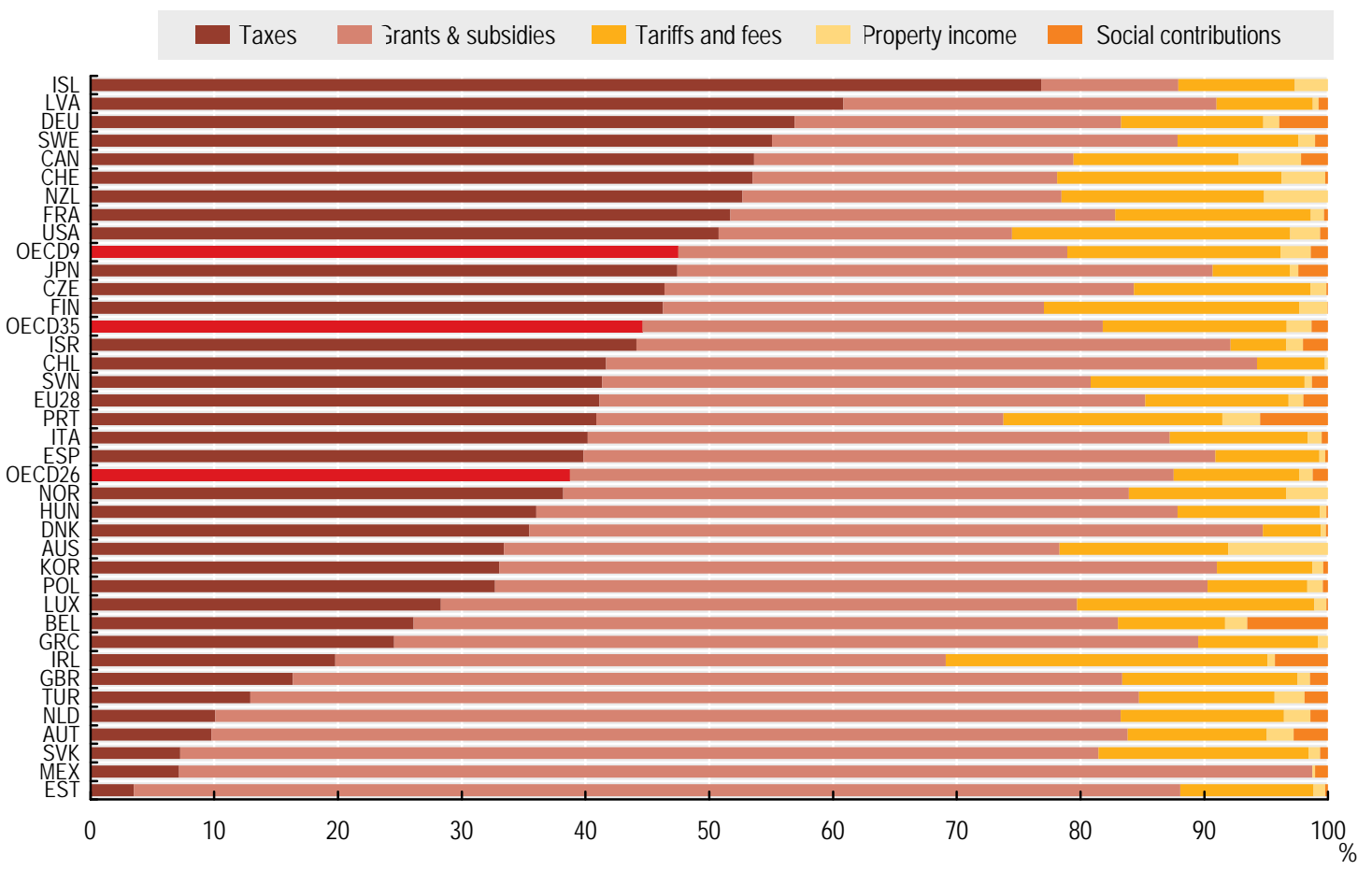

Source: OECD (2018), Subnational Governments in OECD Countries: Key Data.

* Tax revenues in this figure exclude revenues from social security contributions, which are included in the OECD definition of taxes. Please see section A2 of the OECD Interpretative Guide for further information.

\section{Box 2. Taxing power of sub-national governments - A taxonomy of tax autonomy}

The term "tax autonomy" captures various aspects of the freedom subnational have over their taxes. It encompasses features such as subnational government's right to introduce or to abolish a tax, to set tax rates, to define the tax base, or to grant tax allowances or reliefs to individuals and firms. In a number of countries taxes are not assigned to one specific government level but shared between the central and subnational governments (SNGs). Such tax sharing arrangements deny a single SNG any control on tax rates and bases, but collectively SNGs may negotiate the sharing formula with central government..

The OECD Fiscal Decentralisation database has established a framework with five main categories of autonomy (table 1). Categories are ranked in decreasing order from highest to lowest taxing power. Category "a” represents full power over tax rates and bases, "b" power over tax rates (essentially representing the "piggy-packing" type of tax), "c" power over the tax base, "d" tax sharing arrangements, and "e" no power on rates and bases at all. Category "f" represents non-allocable taxes. In order to better capture the more refined institutional details the five categories were further divided into subcategories. Altogether 13 categories were established to capture the various tax autonomy arrangements in OECD countries. 


\section{Table 1. Taxonomy of taxing power}

\begin{tabular}{|c|c|}
\hline & $\begin{array}{l}\text { - The recipient SNG sets the tax rate and any tax reliefs without needing to consult a higher level } \\
\text { government. } \\
\text { - The recipient SNG sets the rate and any reliefs after consulting a higher level government. }\end{array}$ \\
\hline b.1 & $\begin{array}{l}\text { - The recipient SNG sets the tax rate, and a higher level government does not set upper or lower } \\
\text { limits on the rate chosen. } \\
\text { - The recipient SNG sets the tax rate, and a higher level government does sets upper and/or lower } \\
\text { limits on the rate chosen }\end{array}$ \\
\hline $\begin{array}{l}\text { c.1 } \\
\text { c.2 } \\
\text { c.3 }\end{array}$ & $\begin{array}{l}\text { - The recipient SNG sets tax reliefs - but it sets tax allowances only. } \\
\text { - The recipient SNG sets tax reliefs - but it sets tax credits only. } \\
\text { - The recipient SNG sets tax reliefs - and it sets both tax allowances and tax credits. }\end{array}$ \\
\hline $\begin{array}{l}\text { d.1 } \\
\text { d. } \\
\text { d. }\end{array}$ & $\begin{array}{l}\text { - There is a tax-sharing arrangement in which the SNGs determine the revenue split. } \\
\text { - There is a tax-sharing arrangement in which the revenue split can be changed only with the } \\
\text { consent of SNGs. } \\
\text { - There is a tax-sharing arrangement in which the revenue split is determined in legislation, and } \\
\text { where it may be changed unilaterally by a higher level government, but less frequently than once a year. } \\
\text { - There is a tax-sharing arrangement in which the revenue split is determined annually by a higher } \\
\text { level government. }\end{array}$ \\
\hline $\mathbf{e}$ & - Other cases in which the central government sets the rate and base of the SNG tax. \\
\hline f & - None of the above categories a, b, c, d or e applies \\
\hline
\end{tabular}

Note: This is the classification used in the data collection exercise but there may be a need for clarification in the future. For example, the sub-division of the "c" category cannot be applied to sales taxes (including VAT) where the concepts of allowances and credits (in the sense that they are used in income taxes) do not exist. Also, it may be more appropriate to qualify the definition of the "d.3" category to say that the change is normally less frequent than once a year, as specific legal restrictions on frequency may not exist.

Source: OECD Fiscal Decentralisation database - OECD Network on Fiscal Relations, http://oe.cd/fdddoc

Based on these rates, it is possible to categorise countries as highly, medium or low decentralised as specified in Figure 6. When crossing these categories, countries can be grouped into four families based on their degree of subnational spending and tax levels characteristics, which cut across federal versus unitary distinctions, as shown by Figure 6 . 
Figure 6. Categories of fiscal decentralisation by subnational expenditure and tax revenue

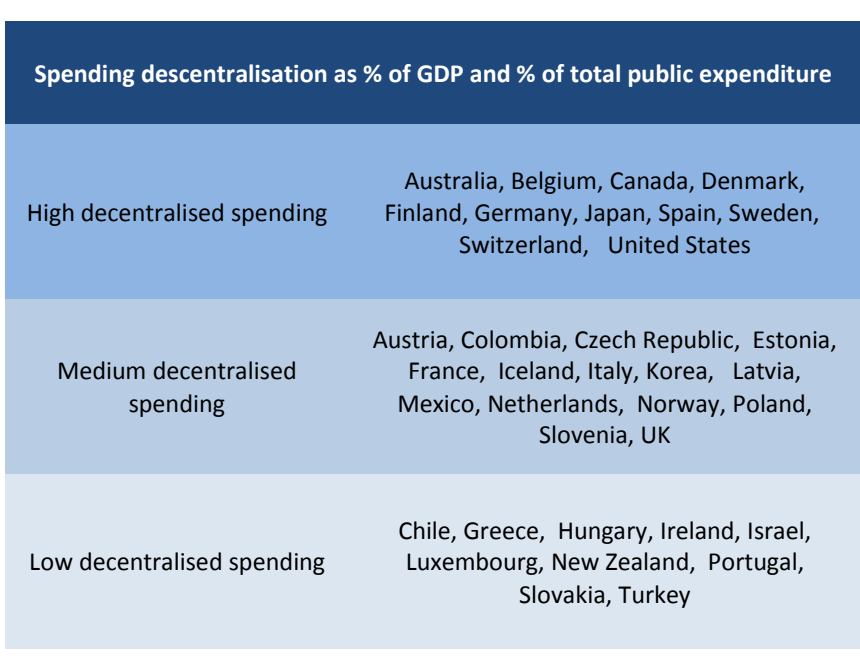

Source: OECD (2017c)

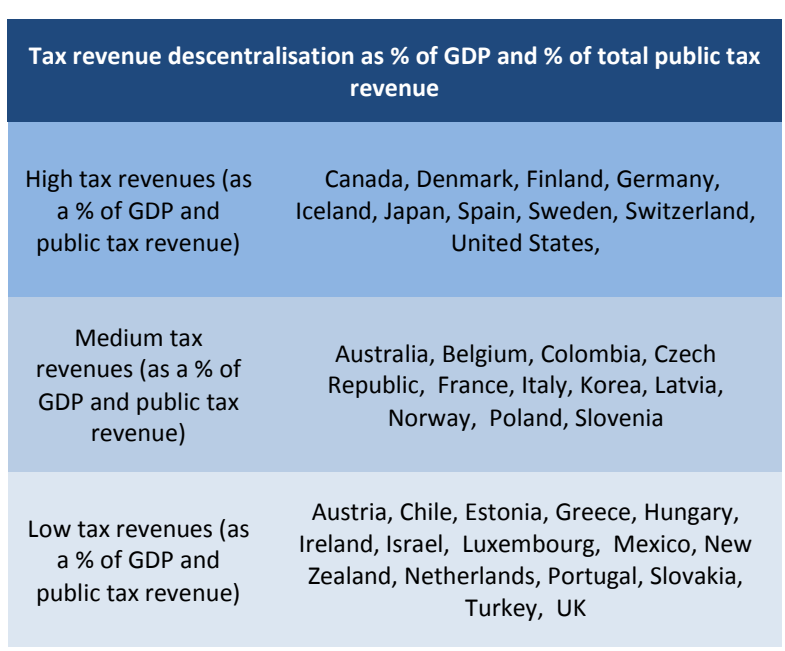

Table 1. Types of countries by level of decentralisation when measured by fiscal indicators

\begin{tabular}{cll}
\hline Type & High decentralised spending and & $\begin{array}{l}\text { Australia, Belgium, Canada, Denmark, Finland, Germany, } \\
\text { Japan, Spain, Sweden, Switzerland, United States }\end{array}$ \\
\hline $\mathbf{1}$ & high tax revenues & Czech Republic France, Iceland, Italy, Latvia, Norway, \\
\hline Type & Medium decentralised spending & Poland, Korea, Slovenia, \\
$\mathbf{2}$ & and medium tax revenues & Austria, Estonia, Mexico, Netherlands, UK \\
Type & Medium decentralised spending & \\
$\mathbf{3}$ & and low tax revenues & Chile, Greece, Hungary, Ireland, Israel, Luxembourg, New \\
Type & Low decentralised spending and & Zealand, Portugal, Slovakia, Turkey \\
$\mathbf{4}$ & low tax revenues & \\
\hline
\end{tabular}

Source: OECD (2017c)

\section{Most decentralised policy areas}

Subnational governments play an important role in OECD countries in service delivery, especially in the education and social area. The bulk of spending in relation to GDP is allocated to education, social protection and general public services (Figure 7). Health and economic affairs/transportation come fourth, before SNG spending on housing and community amenities (supply of potable water, public lighting, urban heating and facilities), recreation, culture and religion and environmental protection (OECD, 2017). 
Figure 7. Breakdown of SNG expenditure by economic function in OECD countries

A. Subnational expenditure by area

(COFOG) as a \% of GDP (2016)
B. Subnational expenditure by area (COFOG) as a \% of total expenditure (2016)
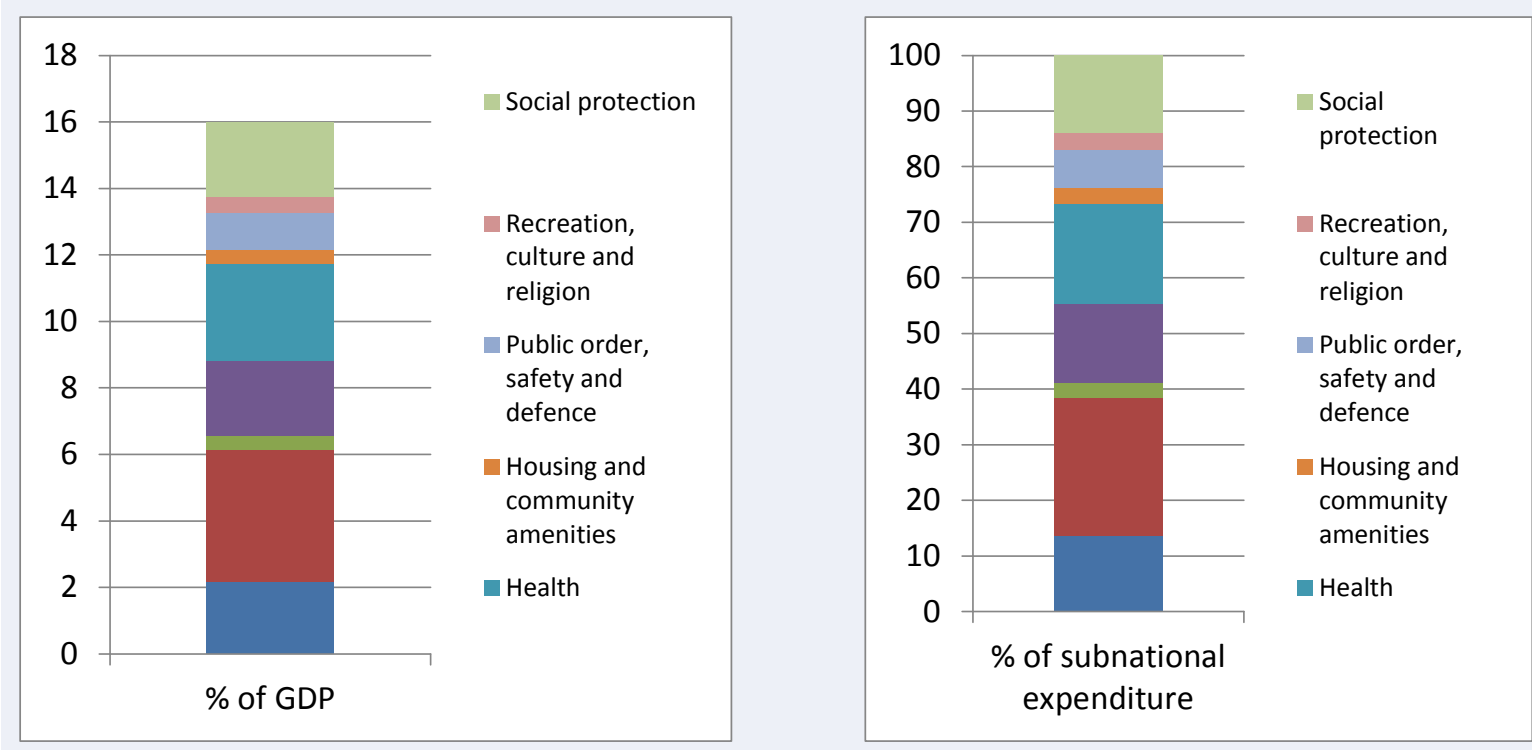

Source: OECD (2018a), Subnational Governments in OECD Countries: Key Data.

A number of countries have made sizeable changes to the assignment of functions in recent decades. Education and economic affairs - mostly transport - were decentralised. However, in some countries these responsibilities have been reassigned to the regional level - rather than the local level ${ }^{8}$. Health care responsibilities, by contrast, have sometimes been re-assigned to central government, although there have also been reforms that go in the opposite direction (OECD 2016b).

The impact of the global crisis in 2008-09 has led to a certain re-centralisation in some countries, at least in the short term - with an increase in central governments grants to support SNGs in the wake of the crisis. This has been only a temporary trend, as it was followed by important cuts in central government grants after 2010-11 in most countries. Re-centralisation trends mainly occur in the fiscal frameworks, with many countries introducing new fiscal rules to control subnational expenditures in the wake of the crisis (almost one third of OECD countries). It is also possible that this enhanced control calls for greater intergovernmental coordination, which enhances the bargaining power of the subnational jurisdictions to broaden their prerogatives in fiscal matters and influence national policymaking (de Mello and Tovar Jalle, 2018).

\section{Real spending power complex to assess}

As mentioned previously, fiscal indicators can be misleading because so-called "decentralised" expenditure can be just in reality "deconcentrated" or "delegated"

\footnotetext{
${ }^{8}$ For example, in Canada, education in several Canadian provinces were centralised to provincial level.
} 
expenditure made on behalf central government. In numerous countries, SNGs have little spending autonomy, especially when they are just the "paying agent" for the central government for example to pay the teachers' salaries or distribute social and welfare benefits to households for example, with no or little choice of how expenses are allocated, such as in Denmark in the social sector. Often, SNGs do not have full autonomy and decision-making authority in their fields of responsibility, functioning sometimes more as agencies funded and regulated by the central government rather than as independent policy makers. Nordic countries for example are in practice more centralised than what might appear from fiscal indicators (Sweden, Denmark, Finland). In many countries a significant share of public spending takes place at lower levels of government, but this information tells little about what subnational governments can actually do autonomously to affect the lives of those living in their territory.

Fiscal indicators such as subnational shares in spending, revenue, and investment tell an important story about where money is spent, but do not capture real spending power. The Regional Authority Index (RAI), the Local Authority Index and the Local governance index (Shah, 2014) are comprehensive attempts to measure the real degree of power of subnational governments - beyond fiscal indicators. They provide a picture of multi-level governance which is closer to reality than when looking at fiscal indicators only. A set of institutional indicators had also been established in 2010 by the OECD Network on Fiscal Relations across Levels of Government, based on a detailed assessment of institutional, regulatory and administrative control central government exerts over various SNGs policy areas (Bach, Blöchliger and Wallau, 2009). Five categories have been established: policy, budget, input, output and monitoring and evaluation autonomy. These indicators were applied in 5 countries and reveal a difference between real degree of autonomy and what fiscal indicators implied (OECD, 2011, 2016).

For each policy area, it is thus necessary to distinguish between different key functions: regulating, operating, financing and reporting. Regarding the financing function, another distinction can be made between current expenditure and investment. The gap between financing and regulation is often quite large in many countries. In the OECD, health, education and social protection or law enforcement weigh heavily on subnational expenditure when subnational governments are in charge of paying medical staff, teachers, social workers or police officers or providing social benefits on behalf of the central government. Often, while subnational governments may simply act as "paying agents" to carry out these delegated functions with little or no decision-making power or room for manoeuvre, these spending responsibilities are a great burden on their budget (OECD, 2016).

\section{Assigning responsibilities at the regional and local levels}

It is rare for competences to be truly exclusive- except in the case of defence or macro stabilisation, which are in general at the central level. Competencies may also be exclusive for certain highly autonomous regions. Most responsibilities - such as transport and infrastructure, spatial planning, environment and water, culture and tourism, communication, or economic development - are shared across levels of government, in particular between the municipal and regional levels.

Assessing a generalised ideal territorial allocation of a given competence, and whether it should be shared or not, is by definition impossible because the conditions in each country and region are distinct and the way responsibilities are assigned depend on the history, geography, institutions, culture, capacities - which differ greatly across countries. 
However, some trends are common to all countries in the way responsibilities are assigned across local and intermediary levels of government. Figure 8 gives an overview of the most common features in the assignment of responsibilities:

Figure 8. Assignment of responsibilities across subnational governments: a general scheme

\section{Municipal level}

- A wide range of responsibilities:
- General clause of competence
- Eventually, additional allocations by
the law
- Community services:
- Education (nursery schools,
preelementary and primary education)
- Urban planning \& management
- Local utility networks (water,
sewerage, waste, hygiene, etc.)
- Local roads and city public transport
- Social affairs (support for families and
children, elderly, disabled, poverty,
- social benefits, etc.)
- Primary and preventive healthcare
- Recreation (sport) and culture
- Public order and safety (municipal
- police, fire brigades)
- Local economic development, tourism,
trade fairs
- Environment (green areas)
- Social housing
- Administrative and permit services

\section{Intermediary level}

- Specialised and more limited
responsibilities of supra-
municipal interest
- An important role of assistance
towards small municipalities
- May exercise responsibilities
delegated by the regions and
central government
- Responsibilities determined by
the functional level and the
geographic area:
- Secondary or specialised education
- Supra-municipal social and youth
welfare
- Secondary hospitals
- Waste collection and treatment
- Eecondary roads and public transport

\section{Regional level}

Source: OECD (2016), Regions at a Glance.

\section{Differences between unitary and federal countries have been reduced}

While one could assume that federal countries will have a greater variety of subnational arrangements and generally greater decentralisation, the relationship is not linear. There are a few federal countries with a low degree of subnational tax autonomy (Mexico, Austria, see Figure 5) and a number of countries that do not call themselves federations, but operate much like them (Spain and Italy). There is also a tremendous variation in arrangements among unitary countries, and this variation has grown in the past 50 years. As decentralization reforms have proliferated in the past half-century, variation among unitary countries has grown and differences between federal and unitary countries have shrunk (Hooghe et al., 2016, 18; OECD/UCLG, 2016h).

What distinguishes federal and unitary countries are the legal/constitutional arrangements concerning shared sovereignty. In most federal countries (Brazil being an exception), the sovereignty is shared between the federal government and federated states which have their own constitution, parliament and government, and large competences, while federal governments have in general exclusive and listed competences such as foreign policy, defence, money, criminal justice system, etc. In most federal countries, the responsibilities of local governments are defined by state constitutions and laws, and they often differ from one state to another. In federal countries, intermediate tiers almost always have some role in "shared rule" of the country-usually in the form of an upper chamber or reserved territorial seats in the legislature. It is common for regional governments in federations to have authority over municipalities in their jurisdiction, 
which also means that variation in municipal autonomy and the assignment of local competences is greater in these countries. It can also be the case that regional governments control municipal organization but not municipal competences, which may be regulated directly by the centre (Spain, for example).

Regions in federal countries tend to have greater policy scope and usually have some authority to implement or shape major social policy areas such as health, education, and social spending. In federal countries, intermediate tiers generally borrow, while in unitary countries there is greater variation.

In unitary countries, the sovereignty is not shared. The assignment of responsibilities is generally defined by national laws. National or regional regulations provide more or less details on local governments' responsibilities, as they often refer to the general clause of competence or "subsidiarity principle", especially for the municipal level, which gives local authorities an explicit freedom to act in the best interests at local level. In quasifederation (Spain) and "hybrid countries", devolved nations (United Kingdom) or regions (Italy) can define, through primary and/or secondary legislative powers, the local government functioning (OECD, 2017b).

\section{Greater variation in the distribution of competences at the regional level}

Overall, there is greater variation across countries in the distribution of competences at the regional level, and less variation at the local level. In contrast to local governments, which are often general-purpose, it is not uncommon for intermediate tiers to be deconcentrated, possess dual executives, or have more limited autonomy, particularly in unitary countries. There are also single purpose or special purpose local jurisdictions in several countries e.g. education, health and sanitation boards and agencies and public/private utilities.

Almost all regions that have general-purpose government play a role in the co-ordination and administration of education (often secondary), health care (specialised and hospital), social services, infrastructure, and economic development, yet levels of authority vary widely. Some self-governing regions have very little policy scope, such as Danish Regioner or Spanish Provincias, or Ukrainian Oblastey. On the opposite end of the spectrum are the Australian States, Quebec in Canada, and the Swiss Cantons, which have full policy autonomy and also authority over immigration, citizenship, or residency.

Some intermediate governments depend completely on the centre and/or their municipalities for funding, while others have greater tax autonomy and thus extensive own resources, and constitutionally protected shares of central government transfers or taxes (tax sharing). Full control of major taxes includes for example the US, Canada, and the Swiss cantons.

In two-tier system of subnational governments, the regional level between the municipalities and the central government, because it operates on a larger scale, usually provide services of regional interest which benefit from economies of scale, generate spillovers, involve redistribution and are required to meet the same standards across the jurisdiction (OECD 2014). The regional tier may also facilitate cooperation and strategic planning (OECD, 2017b). In a three-tier system, like in France, Spain, Italy or Poland, the breakdown can be complex, sometimes resulting in duplication, overlap and coordination challenges. However, over recent decades, the intermediate level has lost many of its powers and responsibilities in favour of regions, which gained more importance. In a majority of countries (except France for example), intermediary governments are now 
mainly responsible for administrative and delegated tasks, and have small budgets and in general no, or only limited, taxing powers (OECD, 2017b).

\section{Distribution of responsibilities at the local level}

In many countries, national or regional regulations provide more or less details on local governments' responsibilities, as they often refer to the general clause of competence or "subsidiarity principle”, especially for the municipal level, which gives local authorities an explicit freedom to act in the best interests at local level. In this case, laws rarely limit or specify local responsibilities but enumerate broad functions instead, except if a particular responsibility is devolved by law to another government level ${ }^{9}$.

In most countries, municipalities have elected general-purpose local government, but the degree of political authority that municipalities have over their responsibilities varies greatly. So does the autonomy of local government to tax and spend. In terms of subnational institutional depth and autonomous representative government, municipalities tend to have the least variation, with elected general-purpose local government existing in many countries (Hooghe et al., 2016). In most countries, municipal governments manage waste collection, local infrastructure and environment, transportation, water and sewer, local urban planning, culture, sporting, and local tourism, local economic development, housing and local public administration (OECD/UCLG, 2016h).

The extent to which municipalities have political authority over the responsibilities they help administer varies greatly, as does the autonomy of the local government to tax and spend. Most local governments have the authority to collect user fees, or charge for municipal services. Borrowing is tightly constrained for most local governments ${ }^{10}$ and when it is allowed there are significant differences in uptake between those municipalities with the capacity to manage investment projects and those without. In Peru before 2002, for example, local governments were permitted to borrow under certain conditions, but only larger cities actually made much of use of this autonomy. (Hooghe et al., 2016; OECD, 2016).

\section{The extent of responsibility sharing varies across sectors}

Because subnational governments are embedded in national legislative frameworks, truly exclusive competences exist rarely, even in federal countries. Shared competences emerge either through explicit legislation or through residual policy acquisition. The need for sharing responsibilities may arise for functional reasons - as is common between municipal and regional tiers around issues of transport and infrastructure, environment and water, culture and tourism, communication, or economic development. It may also arise for financing reasons such as for social services. Major areas of public service provision such as health care and education may be well suited for tiered management and provision. Shared responsibilities that are not explicitly legislated often arise from the existence of residual powers.

The extent of responsibility sharing also depends on the service in question; for example, responsibilities tend to be more often shared in public transportation than in childcare or

\footnotetext{
${ }^{9}$ In a large number of countries local government statutes typically specify residuality and ultra vires principles forbidding local governments to undertake activities not clearly specified by state law or constitution. In the USA, this has an important source of litigation.

${ }^{10}$ Finland is an exception, as municipal governments do not require central approval for borrowing (Hooghe et al., 2016: 371; Council of Europe, 1998; Joumard and Kongsrud, 2003).
} 
elderly care, probably reflecting the network industry character of the former and hence the need for enhanced co-ordination (OECD, 2016b). Some examples of the most commonly shared responsibilities are set out below:

- Physical infrastructure and its related public investment are some of the most commonly shared responsibilities. Nearly $60 \%$ of public investment is channelled through subnational governments (OECD, 2013), though the authority over the projects and use of funds varies widely. Subnational governments are generally responsible for local roads and local transportation infrastructure. Investments with high externalities are generally managed at higher levels of government. This requires effective coordination mechanisms, which does not take place spontaneously and requires central incentives to be put in place. The OECD has endorsed a Council Recommendation in 2014 on Effective Public Investment across Levels of Government, which provides guidance to governments on how to manage this shared responsibility.

- Education is the most common major public service to be shared substantively across multiple tiers of government (OECD, 2016b). It is the single largest budget item for local governments in most countries. On OECD average, education accounted for 25\% of total subnational expenditure in 2014, amounting to almost $50 \%$ of total public education expenditure (OECD 2016a). In most OECD countries, lower levels of government are responsible for managing and funding lower levels of schooling (mainly pre-elementary, primary and sometimes lower secondary education) whereas responsibility for secondary, and in particular upper secondary, schooling is more often retained at provincial/regional or central levels. These functions are sometimes carried out on behalf of central government, with more or less discretion. Central governments establish framework legislation and local governments are usually responsible for maintaining and constructing physical infrastructure and the payment of staff-though in many cases without actual authority over hiring or salary. In most cases primary and secondary education are administered at the local level, but with varying degrees of actual decision-making autonomy for local governments. Greece and Ireland are interesting outliers in which the central government provides education directly (OECD, 2016d). Regional governments may play a significant or negligible role, depending on the multilevel governance and territorial arrangements in the country, but the basic role for the centre and local governments is generally consistent.

- Because of high system complexity, health care is usually more centralised than education, with specific roles for different levels of government but often less autonomy (OECD, 2016d). Subnational expenditure represented 25\% of total public health spending on unweighted average in the OECD in 2013. This share is less than 2\% in several OECD countries where health remains a centralised responsibility, such as Greece, Ireland, Israel, Luxembourg, the Slovak Republic, France or the United Kingdom. At the other end of the spectrum, this share exceeds $60 \%$ in Italy, Spain, Switzerland and the Nordic countries (Norway, Finland, Denmark and Sweden). In these countries, wide responsibilities for planning, organising, delivering and financing healthcare services and infrastructures are decentralised to the municipal level (primary care centres) but especially to the regional level (hospitals, specialised medical services)

- Social assistance or welfare have much greater variation and is more likely to be jointly provided because of the strongly redistributive character of the service. - various programs may exist at different levels of government with greater or lesser co-ordination between them. The United States is illustrative here, with federal welfare benefits and programs administered through the states, in co-operation with local governments, and 
over which states have varying degrees of control. Yet states are free to create their own particular programs for social assistance and often provide autonomy to their municipalities, resulting in great heterogeneity of programmes and coverage. In Brazil, municipal governments have concurrent power over social policy alongside states and the federal government (Hooghe et al., 2016; OECD 2013a). They create, finance, and execute their own social programmes and policies to complement national legislation.

- Land use: National governments and regional governments focus primarily on strategic planning and the provision of policy guidelines. Land use planning is predominantly a local task, even though several countries use guiding land use plans prepared at the regional or inter-municipal level. Most countries do not prepare land use plans for the entire territory of a country, but are sometimes responsible for the preparation of land use plans for areas of particular importance. In all unitary countries except Italy, national governments adopt the framework legislation that structures the planning system. In federal countries, this task is predominantly situated with the federated states. In practice, the consequences of this distinction are small. Few unitary countries tend to have entirely homogenous approaches to planning for their territory, while the federated states or regions within a federal country tend to adopt similar framework legislation. For the character of a planning system, the degree of local autonomy seems to matter more than the degree of regional autonomy (OECD, 2017e).

\section{Box 3. Examples of shared responsibilities in countries}

- In Switzerland, where Cantons have some of the highest levels of autonomy of any regional government, there are few shared major competences in areas of social policy or public service provision. Between local and regional government, competences in regional traffic management, economic development, environment, and flood protection are shared (OECD, 2011). This is a clear example of some of the most common policies shared between local and intermediate tiers for functional reasons.

- Portugal is an example of nested, complementary responsibilities in a more centralised setting. There is no authoritative regional tier, so the central government is the primary policy provider for municipalities. Local government has exclusive competences in the secondary regulation of major policies provided by the centre: urban and rural spatial planning, transport, rural and urban equipment, energy, communications, education, health, housing, social affairs and environment (OECD, 2008).

- Norway is a case in which co-ordinated multilevel governance has been prioritised over clear delineation of responsibilities (OECD, 2007). Explicitly shared responsibilities between county and municipal governments is limited and primarily functional (culture and environment), but the fylker have residual powers and may initiate co-ordinated policy making in many areas (OECD, 2007). Like the other Nordic countries, intermediate governments have taken on significant responsibilities in implementing economic and cultural-education policies (Hooghe et al., 2016: 392).

Source: OECD Territorial Reviews and Hooghe et al. (2016).

\section{Increased asymmetric decentralisation}

A major trend in recent decades has been asymmetric decentralisation. This means that SNGs have differentiated responsibilities, depending on their capacities, population (urban or metropolitan areas), certain characteristics like ethnicity, identify or geographic 
characteristics (Islands for example). This is not a new trend. It has been important since the 1950s, but has accelerated in recent decades. For most of the history of multilevel governance research, the issue of asymmetry has been little assessed. The RAI takes the first systematic look at special status regions. Almost two third of the 81 countries covered by the RAI have some form of asymmetric decentralisation arrangements.

What the RAI reveals also is the extent to which the trend toward asymmetric decentralisation has been rising. In 1950, 45\% of the countries covered by the RAI, and with regions, had some kind of differentiated governance (autonomy, asymmetry, or dependency). In 2010, this figure had increased to $62 \%{ }^{11}$ (Hooghe et al, 2016) (see Figure 9).

\section{Figure 9. Growing differentiation in subnational governance (81 countries)}

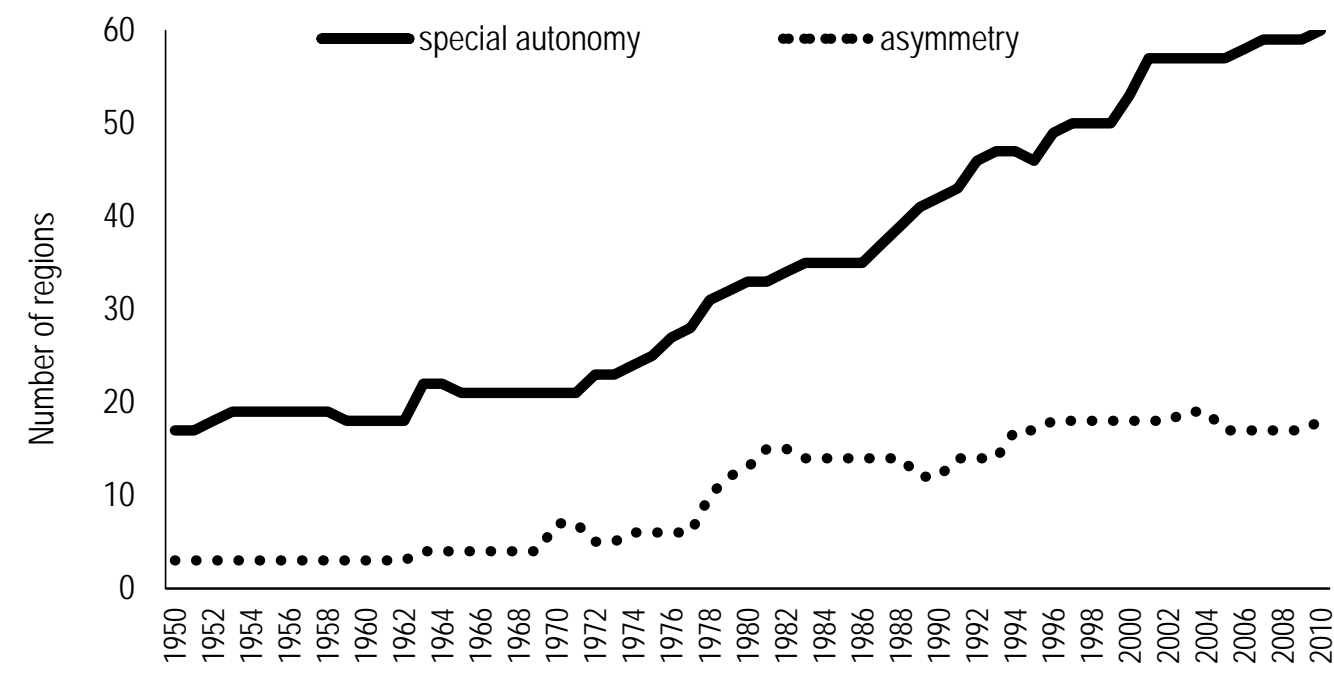

Source: Regional Authority Index (Schakel, 2018)

Trends towards asymmetric decentralisation seem to have accelerated in the past three decades, in particular in the sense of differentiated governance for metropolitan areas, as well as different governance arrangements for specific regions with more capacities. At the local/municipal level, there also appears to be a significant increase in the use of asymmetric arrangements (OECD, 2018).

\section{Metropolitan governance}

While in the 1980s/1990s the trend was rather at the regional level, asymmetric decentralisation trends are now growing at the metropolitan level. Indeed, in recent years, an increasing number of metropolitan areas have gained additional responsibilities, in the fields of public transport, environment, or spatial planning, for example. This reflects a

\footnotetext{
${ }^{11}$ Yet this masks significant transformations because a large portion of the differentiation in 1950 was made up of dependencies (internal colonial arrangements, more or less), whereas in 2010 dependencies had nearly been eliminated and special and asymmetric arrangements had become more common. Of the countries with differentiation in 1950, every one still had differentiated regions in 2010, while 10 of the 24 countries without differentiation in 1950 included differentiated regions by 2010 (Hooghe et al, 2016).
} 
move toward greater institutionalised co-operation (particularly in instances of administrative fragmentation) and integration (OECD, 2015a; OECD, 2015b).

Differentiated municipal governance for metropolitan areas has been increasingly adopted in recent years within the OECD. Capital districts with special autonomy often started out in the mid-20th century with lower levels of authority because of restrictions on representation or other elements of self-rule (Box 4). The number of metropolitan governance authorities of all types created has increased considerably and there has been a renewed momentum in the number of metropolitan governance bodies created or reformed since the 1990s, against the backdrop of the early 1990s recession and the 2008 financial crisis (Figure 10). Currently, around two-thirds of the metropolitan areas in the OECD now have a metropolitan governance body (OECD Metropolitan Governance Survey, 2014).

\section{Box 4. Asymmetric decentralisation through metropolitan governance}

\section{Capital districts}

Capital districts with special autonomy often started out in the mid-20th century with lower levels of authority because of restrictions on representation or other elements of self-rule. Yet these are often the cases that most notably close the gap over time, sometimes even overtaking standard regions as they reach parity in democratic representative institutions and keep or attain greater levels of policy and fiscal autonomy (Brazil’s Distrito Capital, Colombia's Distrito Capital).

Many capital districts have historically had a special status limiting the direct election of the executive and placing that authority with the central government, in contrast to other municipalities that have directly elected local leadership. At the same time, they may have greater fiscal autonomy and policy scope imbued by their special status; Kyiv is an example of such an arrangement. This contrasting distribution of autonomy reflects the dual tendencies of central governments historically to maintain tighter control over capital cities for strategic and geo-political reasons, coupled with an economic efficiency rationale that their higher capacity and complexity requires additional competences in policy scope and fiscal autonomy.

\section{More recent forms of metropolitan governance}

The 2013 French Law on Metropolitan Areas contemplated differentiated governance for Paris, Lyon and Aix-Marseille, to include governance structures with own taxing powers and the shift of competences from regions and departements (OECD, 2015a).

In Italy, a 2014 reform ended two decades of gridlock over metropolitan governance reform and created the legal structure for the introduction of differentiated governance in ten major metro areas-Rome, Turin, Milan, Venice, Genoa, Bologna, Florence, Bari, Naples, and Reggio Calabria - and four additional cities in special regionsPalermo, Messina, and Catania in Sicily, as well as Cagliari in Sardinia (OECD, 2015a).

The OECD also supports plans for metropolitan differentiated governance in Colombia to give greater responsibility to high capacity metro areas and alleviate some administrative burdens in lower capacity areas (OECD, 2016f).

Source: OECD Territorial Reviews and Hooghe et al. (2016). 
Figure 5. Recent waves of metropolitan governance

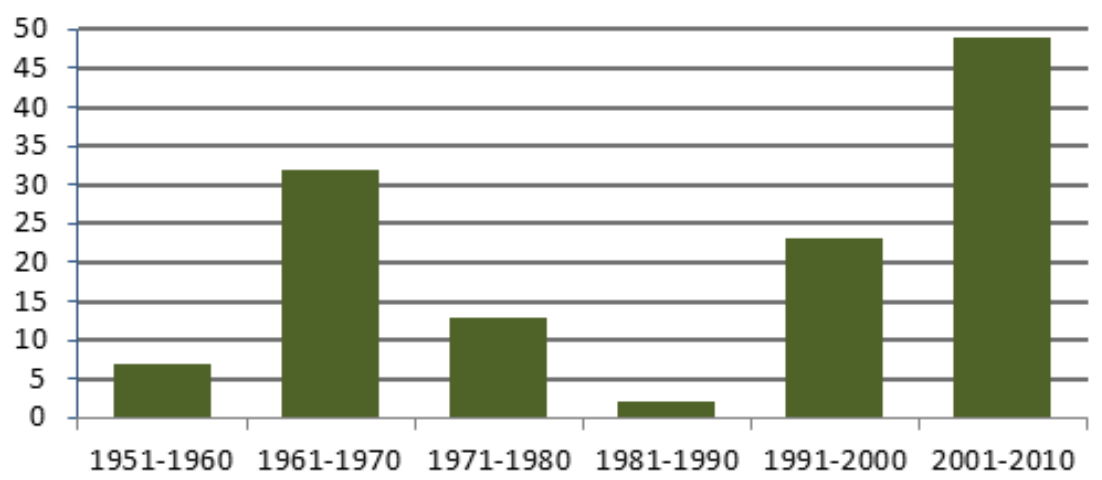

Source: OECD (2017a)

\section{Challenges, good practices and lessons}

\section{Principles from the literature: from theory to practice}

The - extensive - literature on fiscal federalism has provided some general guidelines that provide a point of departure for thinking about the assignment of responsibilities (e.g. Oates, 1999) (see Box 5). The literature recognises that accountability is strengthened if responsibility for a particular function is tier-specific and that allocating fiscal resources and budget transfers among levels of government must come after a clear assignment of spending powers.

However, when looking at country practices, the difference between theory and country experience appears significant, in both developing and developed countries. As seen in Section 1, most of the responsibilities are shared across different levels of government, which implies complex co-ordination systems. Fiscal federalism principles provide useful overarching guidelines, which need to be complemented by lessons from practical experience. 


\section{Box 5. Insights from the literature: key fiscal federalism principles}

Assignment of public services to local or regional governments can be based on various considerations such as economies of scale, economies of scope (appropriate bundling of public services), cost/benefit spillovers, proximity to beneficiaries, consumer preferences, and flexibility in budgetary choices on composition of public spending (Shah, 2007).

Some key principles from the literature are the following:

- Subsidiarity, implying that provision of goods and services should be administered at the lowest level feasible within the national interest. The rationale appears to be that this permits such provision to most closely match the preferences of the people.

- Correspondence, argues that where consumption or use of a particular good or service is limited to the boundaries of a particular jurisdiction, then its provision should be allocated to a subnational government whose boundaries are defined by the spatial benefit (or market area) boundaries associated with this good or service (Oates 1972, 2005; Warren 2005; Williams 2005).

- Recognition of economies of scale in the provision of goods and services, with a case generated for movement of provision to a higher level where it costs less if produced or provided by single jurisdiction rather than separate smaller ones (Williams 2005). Need for a mechanism to resolve inter-jurisdiction spill-overs or spill-ins of benefits (and/or costs) of a particular good or service. In the absence of such mechanisms, economic inefficiency in the form of under (or over-) provision of such goods or services would result.

\section{Taxation powers}

- The principle of fiscal equivalence implies that each level of government should finance its assigned functions with funds it raises itself (Olson, 1969).

- Benefit taxation: subnational governments should rely on taxes with a strong link between the taxes that households and businesses pay and the public services (i.e., benefits) that they receive (Oates and Schwab, 1988).

Source: OECD (2016b); Shah (2007); Smith (2006).

Overall, countries share similar challenges, with different degrees based on the specific nature of each MLG system: (i) unclear assignment of responsibilities; (ii) resources and capabilities bottlenecks and (iii) co-ordination challenges, both vertically and horizontally.

However, OECD countries have made progress in recent decades on several fronts. This section will review the challenges and progress made and seeks to identify some guiding principles for effective assignment of responsibilities, based on experience, conducive to regional and local development.

\section{Unclear assignment of responsibilities}

The lack of clarity in assignment is mentioned in Territorial Reviews as among the most important challenges in multi-level governance. When looking at other sources, in particular OECD Economic Surveys or IMF studies, one can see that this is true in unitary countries - but also in some federal countries - like Australia or Germany for 
example. The challenge of unclear assignment is also repeatedly mentioned in IMF and World Bank country studies for developing countries.

Lack of clarity in the assignment of responsibilities makes service provision and policy making more costly; it also contributes to a democratic deficit by creating confusion among citizens regarding which agency or level of government is responsible. Holding leaders accountable for shortcomings or policy failures is almost impossible without a clear distribution of responsibilities. A lack of clear assignment of responsibilities also hinders efforts at transparency and citizen engagement when the public does not know who ultimately is responsible for important public services.

The Territorial Reviews find that sharing responsibilities in an open-ended fashion sometimes hampers financing and accountability for specific parts of policy provision. Indeed, laws rarely limit and specify local responsibilities but enumerate broad functions instead, except if a particular responsibility is devolved by law to another government level. Sharing responsibilities in such an open-ended fashion (clause of general competency) often leads to competing and overlapping competences and a lack of visibility and accountability concerning public policies (OECD, 2017a).

The problem is not just that policy areas are not clearly defined, it also comes from the fact that functional responsibilities - i.e. financing, regulating, monitoring - within each policy area - are often not clearly allocated, or not consistent. The respective roles on regulation or normative design, financing, and implementation or actual delivery often remain unclear - thus impeding action. For example, in Mexico, subnational spending in education or health is dominated by personnel expenses, while spending on goods and services (including investment) is limited, and functional spending responsibilities are not clearly defined (IMF, 2009). In Chile, until the recent law on municipal staff adopted in 2016, municipalities did not have the possibility to adapt their human resources, quantitatively or qualitatively, to their new functions (OECD, 2017b).

Where clarity is lacking, much higher levels of multilevel co-operation are necessary. For this reason, lack of clear assignment of responsibilities is particularly costly in developing countries that may not have the resources or capacity to set up institutions for vertical and horizontal co-ordination. The Philippines illustrates this challenge: competences in major arenas - such as infrastructure - are shared, yet because of unclear ownership no one knows who is ultimately responsible for what. The result is that pressing infrastructure needs go unanswered, particularly for the vulnerable. 


\section{Box 6. Examples of lack of clarity in the assignment}

- In Brazil, there is a lack of clear division of responsibilities in a number of areas, such as health care, education, social security, welfare, agriculture, and food distribution, environmental protection, sanitation and housing (OECD, 2013).

- In Chile, at the municipal level, the current system of responsibilities is quite complex with few exclusive competences and 13 shared competences whose dividing lines between central or municipal interventions are not well established and subject to change. Additional tasks are regularly attributed to municipalities without financial or technical compensation. Shared responsibilities, especially education and health, are a significant burden on municipal budgets (see chapter 2). Until the recent law on municipal staff adopted in 2016, municipalities did not have the possibility to adapt their human resources, quantitatively or qualitatively, to these new functions (Chile, 2017)

- In Colombia, the cumbersome allocation of responsibilities across different levels of government makes the funding system complex and it is difficult to assess if a specific service, whose management corresponds to different layers of the administration, is appropriately financed (OECD, 2014).

- In Finland, the 2007 highlighted that many provincial, regional and local actors share responsibility, which entails problem of co-ordination, with possible overlapping.

- In France: a 2017 report from the Cour des Comptes suggests to go further in the clarification the allocation of competencies between departments and intercommunalités and to strengthen efforts to mutualise functions across municipalities. The report also regrets that the clause of 'compétence générale' was only suppressed for regions and departments, and not municipalities, thus not allowing a full clarification of the roles of the different tiers of government (Cour des Comptes, 2017).

- In Mexico, expenditure responsibilities are not clearly defined, with health and education being two main areas of overlapping responsibilities (IMF, 2009, OECD 2005).

- In Peru a lack of clear delineation of competences has produced unco-ordinated overlap and lack of ownership (OECD, 2016).

Source: OECD Territorial Reviews and French Cour des Comptes, 2017

\section{Challenges for specific policy areas}

Such unclear allocation of responsibilities and functions is particularly notable for policy areas which are the most 'shared' across levels of government, in particular infrastructure (transport), education, spatial planning, health or labour market policy:

- Transport: Reviews highlight that the transport assignment is often unclear and that functional spending responsibilities tend to be not clearly defined. In Poland, there are overlaps both across local governments and with state agencies/voivod offices in particular for transport, health and employment policy. Road maintenance in particular is the responsibility of local governments and various tiers of the state administration at the regional office and voivodship levels. In Mexico, the competencies for road construction and maintenance are split between the three levels of government, with construction mainly executed by federal and state governments, and maintenance mainly carried out by the states or municipalities. In 
Ukraine, municipalities are responsible for infrastructure and its maintenance. At the same time the road agency of the national government is responsible for roads including their paving and repaving. In the case of a bridge (infrastructure) if its road-surface requires repaving, there is a high risk of inaction as neither level of government is compelled to act. Is repaving the bridge's road a function of bridge maintenance and thus a municipal competence (requiring the use of municipal funds); or is it a function of road maintenance and thus a central government responsibility covered by the State Budget? The answer is not clear, and the result is that the bridge's road remains in disrepair (OECD, 2018).

- Education: in most OECD countries, lower levels of government are responsible for managing and funding lower levels of schooling (mainly pre-elementary, primary and sometimes lower secondary education) whereas responsibility for secondary, and in particular upper secondary, schooling is more often retained at provincial/regional or central levels (OECD, 2017b). These functions are sometimes carried out on behalf of central government, with more or less discretion. This type of arrangement where sub-sectors of schooling operate under different political and administrative jurisdictions may raise significant challenges concerning efficient use of resources (risks of competition, duplication and overlaps) and co-ordination of policies and actors. It generally involves clearly defining the division of labour between different levels of government and putting in place appropriate coordination mechanisms and collaborative practices under the general umbrella of the Ministry of education (OECD 2016h).

- Health: Health care systems seem to suffer greatly from a lack of clear division of responsibility, duplication, cost shifting, and scale inefficiencies (OECD/FN, 2016). In Poland for example, the Review mentioned an artificial division in Poland in social care/health between the municipal level, poviat and regional level (OECD, 2008a). In some countries, particularly developing and transition economies (notably Russia or China), it has been acknowledged that the devolution of health expenditure, in the absence of equalisation transfers, has led to increased regional discrepancies at the local level in access to health services (Ter-Minassian, 1997).

- Labour market policy is often shared, with frequent overlaps across levels of government (OECD, 2002). Greater difficulty arises when several levels of government share the same functional responsibilities, within the same responsibility sector. For example in Canada, problems arise as two government levels (federal government and provinces) are each responsible for funding one of two complementary financial assistance regimes. This system provides incentives to pass the buck to the other layer (OECD, 2003). In Poland, accountability remains unclear concerning employment policy ${ }^{12}$. This results in a lack of coherence across the various responsibilities on labour market policy at the local level, which may affect its efficiency. For example, there is a critical lack of data on labour mobility at the local level, as no agency is officially in charge of collecting these data (OECD, 2008).

12 Although 16 regional labour offices have been created, marshal offices have also taken some responsibilities in the fields of scholarships and life-long training. In addition, poviats retain some responsibilities in labour market policy, through the poviat labour offices. 


\section{Box 7. The case of education: examples of Austria and France}

There are different manners of sharing responsibilities, which are not exclusive, based on the level of education, on the functions or on the financing. The latter is, among others, the way chosen by France and it is envisioned in Austria.

In Austria, the educational system was also strongly centralised for historical and political reasons. According to the general clause of Article 15 (1) of the Constitution, education is one of the exclusive competencies that are assigned to the federal government with public security, taxes, civil and penal law, industrial affairs and heath care. However, the Bundesländer have the constitutionally guaranteed right to execute some federal laws, especially in the area of education. This has led to a complex distribution of responsibilities between the federal government and the states. For example, lower secondary schooling is currently offered by both the federal level (first stage of academic secondary schools) and the provincial level (within so-called New Secondary Schools). Education policy is a controversial topic with intense debates. A reform is currently under discussion in order to clarify the division of responsibilities between the federal government and the regional states (Bundesländer) seeking ways to streamline the governance and funding of the Austrian school system There are different options but one appears to be a feasible compromise which would consist in putting Bundesländer in charge of all investments and maintenance and leaving the federal government in charge of the funding and allocation of teachers through new Education Directorates based in each province (OECD 2016h). In Austria, subnational education expenditure accounted for around $17 \%$ of total subnational expenditure i.e. $46 \%$ of total public education expenditure.

In France, the educational system was historically very centralised. Decentralisation reforms in 1982-1983 and 2003-2004 resulted in a mixed system. The degree of direct management and control from the Ministry of Education has diminished considerably. However, the central government retains responsibility for the national curriculum and general educational goals, recruitment, training, management and remuneration of teachers (schools and university), while subnational governments are in charge of investment and maintenance responsibilities for the pre-elementary and primary schools (municipalities), the collèges (departments), and the high schools or lycées (regions). Since 2004, subnational governments are also responsible for recruitment, management and payment of technical and administrative staff. They are also responsible for school transport, meals and extra-curricular activities. Subnational governments nevertheless receive transfers from central government intended to cover the bulk of their education expenditures to cover operational expenses (other than teaching staff), equipment and building infrastructure (OECD 2006, OECD 2007). In 2014, subnational education expenditure accounted for around $14 \%$ of total subnational expenditure, representing $31 \%$ of total public education expenditure.

Sources: OECD (2017b) Multi-level Governance Review of Chile [OECD 2016a, OECD 2016i, Nusche, D., et al. (2016), OECD 2006, OECD 2007].

\section{Unclear assignment with deconcentrated state administrations}

Another type of challenge is linked to the often unclear allocation of roles between subnational governments and deconcentrated central state administrations in territories. Although the prevalence of deconcentrated central state administrations alongside autonomous subnational government in the same territory has diminished in the past decades, the challenges remain important in some countries like Estonia, Finland, 
France $^{13}$, Hungary, Greece, Italy, Poland, Sweden, Turkey or Ukraine. Reconsidering these complex and often opaque arrangements could help facilitate the clear assignment of responsibilities.

This was highlighted as a challenge in the Review of Sweden (OECD, 2017) for example. The Swedish elected landstinge formally share authority with the deconcentrated central government länsstyrelser for the same territories, though greater authority has shifted to the landstinge in recent years (Hooghe et al., 2016: 396). Competences in the administration of health, education, economic development, transport, housing, and land use are shared between municipal and county governments (OECD, 2010). The 2017 Review recommended bringing greater coherence to the county governance framework by re-evaluating task allocation among all levels of government, paying specific attention to County Administrative Boards and streamlining state agency areas of operation to match those of territorial boundaries (see annex A).

\section{Good practices and some lessons}

Although important challenges remain in many countries, both Territorial Reviews and the Regional Authority Index reveal a trend towards greater clarification in some countries in the assignment of responsibilities over time. Even if progress was made, the topic remains challenging in most countries, as for shared rule, even in the presence of very precise specification in the legislation, in practice lack of clarity may arise.

Most of the countries that have fairly clear delineation of responsibilities and functions today did not start out that way, but have realized the importance of such reforms and addressed them over time (.e.g. Japan, Spain or Switzerland for example).

- In Japan, the 1988 Municipal Government Act (loi communale) provides a reference framework for the distribution of responsibilities across levels of government, making a distinction between mandatory responsibilities (including some which are shared with central government or delegated) and optional responsibilities. The 1999 decentralization law eliminated opaque central decision-making on local responsibilities and clarified competences more generally. Subsequent waves of reform have continued to develop the goals of greater municipal autonomy, clear delineation of responsibilities, and proper financing (OECD, 2016a; OECD, 2017).

- In the Netherlands, the Dutch decentralisation reform aims to reallocate competences between the different levels of government, in particular by re-enforcing provincial and municipal responsibilities and by establishing simpler and clearer division of responsibilities between the different public actors, avoiding the overlapping of functions (OECD, 2014).

- In Norway: most responsibilities are shared across levels of government, but a strong history of co-ordinated multilevel governance mitigates those challenges. Still, to maintain such an arrangement, greater clarity of the role of the centrally appointed county governor, and expanded inter-municipal co-operation are needed (OECD, 2008c: 21-2).

- Spain conducted an important reform in 2013 to clarify municipal competences and prevent duplication, under the principle of "One Administration, one competence” (see

\footnotetext{
${ }^{13}$ It was also highlighted as an important challenge in the Review of Aix-Marseille (OECD, 2014).
} 
Box 8). It aims at reducing competences which are not attributed by law or delegated by other administrations without the adequate resources (known as "improper competences”). This clarification of powers at the municipal level seeks to guarantee appropriate funding to cover core competences, while eliminating or greatly restricting expenditure on non-core competences (see Box 6).

- Switzerland is an example of clearly delineated responsibilities and co-operation in areas of shared competence in a federal country. The Federal Reform (2004-2008) encouraged co-operation between the cantons, reassigned competences more clearly to either the federal or cantonal governments, and created mechanisms for the formalisation of co-operation agreements (OECD 2011a).

\section{Box 8. The Spanish Local Reform: clarifying municipal powers}

Spain is a strongly decentralized country where autonomous communities and municipalities manage more than 50\% of total public expenditure. In 2013, the Spanish Government approved a reform reforming the 7/1985 law governing local authorities, aimed at the rationalization of administrative structures and, therefore, the reduction of local public expenditure.

One of the key objectives of the Local Reform was to clarify municipal competences and prevent duplication, under the principle of “One Administration, one competence”. It aims at reducing competences which are not attributed by law or delegated by other administrations without adequate resources (known as "improper competences"), as this situation jeopardized local public finance.

The Local Reform intends to improve the definition of local competences. To do so, a list of core competences has been established. Competences which are not included in this list are referred to as "non-core competences". In the event of any agreements delegating competences from upper levels of government - usually, the Autonomous Regions - to lower levels of government, it is compulsory to provide corresponding resources earmarked for financing the services involved.

Source: OECD (2014)

\section{Level to which policy areas should be assigned}

The way responsibilities should be assigned within each policy area depends on a large set of parameters and is largely context dependent. The question is not of a clear-cut allocation of responsibilities, but rather of how to manage shared functions and responsibilities. However, some common principles - in terms of scale, economies of scope, apply in all contexts. For example, issues such as regional roads, regional economic development, regional planning, higher education are often managed at the regional level in OECD countries, due to the management of externalities and cost/benefit spillovers. These topics require by definition a certain scale to focus on urban-rural linkages, so regions are better placed than municipalities to handle them.

Neither Territorial Reviews nor Economic Surveys recommend shifting more responsibilities to lower levels of government. Only in a few cases do the reviews suggest this kind of shift - for example in the case of Chile (OECD, 2017b). Most Economic Surveys also avoid mentioning the level to which a certain function or policy area should be assigned (OECD/ECO 2016). Some of the few recommendations made by Territorial Reviews and Economic Surveys are the following: 
- Infrastructure: national framework conditions are essential, but most of infrastructure investment is decentralised in OECD countries - requiring sound coordination mechanisms, as highlighted by the OECD Recommendation on Effective Public Investment across levels of government (OECD, 2014). The local level often lacks the scale to address urban-rural linkages so the regional - or/and metropolitan levels - should play a role in strategic planning to ensure balanced development.

- Education: Economic Surveys and Education Reviews show that educational objectives and monitoring should be assigned to higher government levels, while school (and, in some cases, teacher) management should be fully assigned to the subnational level.

- Health: No clear-cut recommendation emerges from Reviews, but a growing number of countries are transferring health responsibilities (notably specialised health care) to the regional level. It was the case in Denmark with the 2007 reform: while municipalities gained responsibilities for social welfare and education, making them responsible for most citizen-related tasks, the five new regions were granted responsibilities for healthcare services, including hospital services. In Belgium, communities and regions gained additional competencies in the framework of the 6th State reform of October 2011, which transferred further competencies in health, including hospital infrastructures, mental health services and preventive medicine. In Finland, a new reform is currently discussed consisting in transferring municipal health responsibilities to future self-governing regions (OECD, 2017b).

- Land use: Land us is typically a local responsibility, but national and regional governments should consider the incentives that their fiscal systems provide for the planning policies of local governments. Ideally, fiscal systems should provide incentives that are in line with the spatial objectives of the higher level governments. If national or regional governments aim to constrain development, it should not be fiscally attractive to local governments and vice versa. National and regional governments have a critical role to play in this regard by establishing frameworks to support integrated planning across functional territories. (OECD, 2017e).

\section{Respective roles need to be mutually understood}

Clear assignment of responsibilities is the entry point that should determine the entire decentralisation process (OECD 2017b). If expenditure responsibility in a broad area (e.g. education or health) is necessarily shared, then respective roles in segments of this area need to be agreed and mutually understood, with co-operative arrangements put in place to ensure appropriate ongoing co-ordination between these segments to ensure they mesh well together at key transition points (Warren 2006; Wilkins 2004). Clarity in the assignment should particularly be watched in unitary countries with three tiers of government, particularly for the intermediate level.

Lessons from the OECD work show that bringing clarity does not necessarily means big changes, territorial reforms, or shifting responsibilities to lower or higher levels of government. Reviews tend to focus more on the recommendations to clarify the way functions are assigned, or strengthen co-ordination mechanisms, rather than on recommendations to shift the level of responsibility. Clarity and balanced assignment were found by Economic Surveys and Territorial Reviews to be more important prerequisites than determining the government level to which policy areas should be assigned (OECD, 2016b). 
Equally important than the clarity in the assignment of sector responsibilities, is the clarity in the different functions that are assigned, within policy areas - financing, regulating, implementing, or monitoring. Where concurrent sectoral responsibilities exist, responsibilities for regulation, financing, and delivery and implementation should be allocated explicitly across the different levels of government and 'grey areas' in the way functions are assigned should be avoided. For example, a recommendation of the forthcoming Review of Ukraine is to "better clarify the attribution of responsibilities and functional designation in transport service provision and infrastructure maintenance between oblast, rayon and hromada levels of government” (OECD, 2018).

It is important to ensure balance in the way various policy functions are decentralised, to allow for complementarities across decentralised policies and integrated policy packages, for effective territorial development approaches (OECD 2016b, OECD 2014). An effective regional or local development strategy requires a balance in the way policy areas are decentralised. If decentralisation only takes place in 2 or 3 policy areas (like health or housing), this will prevent subnational governments from designing integrated regional and local development strategies. For example, OECD analyses point out that infrastructure investment alone has little impact on regional growth unless it is associated with human capital and innovation (OECD, 2009). Balanced decentralisation allows subnational governments to better co-ordinate policy and to reap economies of scale and scope across functions (OECD, 2016a).

\section{Resources and capabilities bottlenecks}

OECD Territorial Reviews and Economic Surveys - as well as IMF and World Bank studies - find that the resources and capabilities bottlenecks of subnational governments are among the most daunting challenges for them to exert their responsibilities. These challenges are of course more acute in developing countries, but they are also present in most developed countries.

\section{Main challenges}

\section{Lack of resources and fiscal autonomy}

These are linked to the lack of clarity challenge, as a lack of clarity in the assignment does not allow guidance in the assignment of revenues i.e. what type of revenues for what type of responsibilities. Revenues' sources (tax, fees, charges, grants, etc.) greatly depend on the nature (exclusive or shared) and area of responsibilities (transport, education, health, social inclusion, etc.).

One of the most frequent challenges, particularly in developing countries or countries at an early stage of decentralisation, but also in developed countries, is the misalignment between responsibilities allocated to subnational governments and the resources available to them. In the most extreme cases, unfunded mandates - where subnational governments have the responsibility to provide services or manage policies but without the requisite resources-are common.

Another important challenge is the lack of fiscal autonomy for SNGs to exert their responsibilities. In all OECD countries spending is more decentralised than revenues. However, a minimum degree of fiscal autonomy is required to allow SNGs to make better use of public resources, targeted to local needs. The most frequent recommendation from Economic Surveys is to align subnational revenues with subnational spending responsibilities (OECD, 2016b). 
Box 9. Examples of misalignment between spending responsibilities and revenues

- In Mexico, the autonomy of municipal government has been and is still severely limited, rendering in the weakest tier of the Mexican government. They have no legislative function and can only make regulations within the framework of state and federal laws. Many municipalities and some states have faced obstacles when trying to administer the budget or raise taxes, for lack of institutional capacity. The fiscal gap, the difference between taxing power and spending responsibilities is significant compared to other OECD countries.

- In Peru, the Territorial Review highlighted the misalignment between responsibilities allocated to subnational governments and the resources and capabilities available to them, which generates a systemic problem in relation to lack of accountability for outcomes. The ill-defined responsibilities were transferred simultaneously to all regions independently of their capacities. The organic laws of the executive, regional and local governments respectively provide more detail on the organisation and competences of the latter. These laws show that there is very strong overlap between the missions and competencies across all levels of government.

- The Territorial Review of Poland (2008) highlighted that Poland needed to think about longer-term options for better matching competencies and resources in some areas, particularly at the regional level.

Source: OECD Territorial Reviews.

In many countries, transfers to SNGs are almost entirely earmarked by central government, thus limiting strongly the subnational fiscal autonomy and the ability to tailor policy answers to local needs. This calls for output based specific purpose fiscal transfers (Boadway and Anwar Shah, 2009).

The paradox of decentralisation trends in recent decades is that they went hand in hand with an increase reliance on conditional grants. Fiscal decentralisation has led to increased subnational responsibilities in the area of spending, while at the same time subnational governments have become more dependent on central governments for their resources (Bergvall et al., 2006 ${ }^{14}$ ). In Chile for example, most grants are awarded to projects that meet national policy directions, standards and norms defined by central administrations without taking into account local characteristics and needs (OECD, 2017). These earmarked subsidies are allocated to specific tasks or projects and come with guidelines and stricter controls, reducing municipalities' decision-making powers.

Non-earmarked grants are usually more efficient funding instruments than earmarked grants (Bergvall et al., 2006), unless a distinction is made between different types of specific purpose transfers (Boadway and Shah, 2009). Nevertheless, there are some cases where earmarked grants can be used in an efficient way for financing subnational services. Such cases are particularly likely to occur with temporary risk-sharing and co-

\footnotetext{
${ }^{14}$ There are several reasons behind the increased use of central governments grants, notably the need to: (i) compensate vertical fiscal imbalances; (ii) prevent regional disparities and correct horizontal imbalances across jurisdictions; (iii) meet central government requirements in service delivery (Bergvall et al, 2006).
} 
operation projects or programmes. In the latter case, earmarked discretionary grants can be used to co-fund projects (Bergvall et al., 2006).

The situation is worsen when the allocation of transfers is unstable, unpredictable, or untransparent. The Territorial Review of Ukraine (OECD, 2013) stressed that the lack of transparency in the allocation of transfers generates uncertainty in the lower levels of government, hindering the possibility to make medium-/long plans.

\section{Lack of capabilities}

Beyond the fiscal capacity issues, reviews repeatedly report the lack of adequate capacities - in terms of staff, skills, expertise, scale - to address complex issues such as strategic planning, procurement, infrastructure investment, performance monitoring, etc. The OECD-CoR survey results of the 2015 survey on subnational obstacles to investment have shown that institutional capacities of SNGs vary enormously within countries, in all countries surveyed (OECD/CoR, 2015). As stated by Andrés Rodriguez-Pose, "capacity deficits in numerous local and regional governments, especially in lagging areas, may undermine even the best development strategies and possibly exacerbate the negative aspects of decentralization, such as corruption and clientelism" (Rodriguez-Pose, 2008).

Municipalities with very small populations have a smaller pool from which to select leaders and local managers, not to mention service providers. They lack the scale to address certain complex issues, in terms of procurement or public service delivery. Large municipalities face different logistical challenges. While capacity is generally higher, the complexity of transport networks, urban planning and infrastructure provision also increases dramatically.

In many countries, the way responsibilities are assigned to SNGs is homogeneous on the territory: all SNGs regardless of size are responsible for delivering the same set of public services. This was mentioned as a particular challenge on reviews on Chile, Colombia, or the Netherlands for instance. However, the high degree of variation in municipal capacity and very different challenges across territories make uniform service delivery unrealistic and often impossible. The lack of flexibility to adapt the organisational structure of municipalities to local characteristics and demands also hinders capacity building at the local level.

The risk of such heterogeneous capacities is the increase in regional disparities. Indeed, SNGs with higher capacities will benefit from funding opportunities - like competitive grants, external financing, PPPs. For example, in Chile, the system of financing subnational investment, often based on open competition, often disadvantages small municipalities that do not have the technical or "relational" capacity to prepare the projects and compete in a bidding process. Bigger municipalities, or those with better technical capacities to develop projects, are in a better position to attract more investment resources. This system adversely affects rural municipalities, and might contribute to increasing rural-urban disparities (OECD, 2017b).

\section{Good practices and lessons}

Territorial Reviews, Economic Surveys and recent work on multi-level governance of public investment highlight different types of lessons to address the broad capacity challenge. They can be summarised under the following headings: 
a) Align responsibilities and revenues and enhance subnational fiscal autonomy

Clear assignment of responsibilities is critical, as it guides the assignment of revenues i.e. what type of revenues for what type of responsibilities. Economic Surveys mostly recommend enhancing subnational fiscal autonomy, through an increase of property tax revenues and a ceding of a portion of income taxes to lower tiers of government (OECD, 2016b). The OECD, the IMF and the World Bank all converge on the fact that control over a portion of subnational resources is key to promoting accountability of SNGs. Empirical analysis conducted by Andrés Rodriguez-Pose have shown that sub-national governments with their own revenue source respond better to local demands and promote greater economic efficiency (Rodriguez-Pose 2009, 2015). The assignment of ownrevenue sources to subnational governments must take into account economic considerations (such as the degree of mobility of the tax base), as well as institutional ones, in particular the capacity of the subnational tax administrations (IMF, 2009).

The share between earmarked and non-earmarked grants depend largely on the degree of subnational governance capacities, but a system which is relying almost solely on earmarked grants is not conducive to accountability and pro-active approaches to development. In all cases, the formulae for determining central government transfers, grants, and earmarked funds from the centre to lower levels of government should be transparent and non-discretionary. Equalization transfers may be put in place, but are not enough to prevent from increasing regional inequalities. Equity concerns should be mainstreamed into multilevel governance planning. Inclusive territorial development may imply in particular: (i) asymmetric decentralisation arrangements; (ii) a consistent longterm focus on subnational capacity building (see below).

\section{b) An equivalent attention should be granted to human resources}

More financial resources need to be completed with the human resources capable of managing them, and too often this dimension is under-estimated in decentralisation reforms. Appropriate capacity levels are crucial both at the subnational levels level but also at the central level to define standards, manage, monitor and evaluate performance. Often decentralisation policies and reassignment of responsibilities go hand in hand with a reduction in the number of central government employees, and an increase of subnational government employees. Subnational governments should have the responsibility to monitor employee numbers, costs and competencies (OECD, 2017).

Capacity building for subnational governance goes beyond a narrow approach focused on workforce improvement activities. Capacity development at the local level, particularly in poor or very small municipalities, must be actively supported with resources from the centre - in unitary countries, or from federated states in federal countries. Capacity building must therefore be a co-ordinated effort both vertically and horizontally and be tied into equalization, public investment and regional development policies.

The priorities in terms of technical support to SNGs are around the issues of financial management and procurement, which are often areas with critical lack of capabilities. Subnational capacity building, however, requires the long-term commitment of resources and is tied to improvements in education and civil service institutions.

\section{c) Asymmetric approaches}

As highlighted in section 1, an increasing number of countries are using differentiated/asymmetric approaches when assigning responsibilities, based on population size, rural/urban classification and fiscal capacity criteria. Asymmetric 
decentralisation is increasingly recognised as an interesting way forward to improve and strengthen decentralisation, as it is currently experienced by Colombia and increasingly adopted for various reasons in France, Italy, Spain, Sweden and the United Kingdom (Box 8). Increasingly, large cities may have responsibilities for some services which are provided directly by the centre in other areas.

Municipalities with greater capacity may be granted additional competences to promote growth and innovation, particularly in large metropolitan areas that are important economic and population centres facing complex co-ordination challenges demanding higher levels of co-ordination at the local, intermediate, and central levels. Geographically peripheral or unique regions may also be accommodated through asymmetric arrangements. Asymmetric arrangements may serve as a crucial safety valve for allowing the diversity of historic regions or nations within a state to maintain their unique heritage without giving rise to separatist movements. In contrast, special status may be used by the centre to deal with "problem" regions or those of strategic importance, exerting deeper central control. Indigenous territories are often a complex mix of special status to permit control from the centre combined with special rights conferred in the wake of indigenous demands for greater self-rule or control of their own resources.

There are different ways to implement asymmetric decentralisation. It can be done by granting a special political status to only some regions or municipalities, assigning differentiated powers and responsibilities, defining dissimilar financing arrangements (in terms of taxing or borrowing power for example), or imposing different norms or requirements (e.g. accounting, reporting, audit, public procurement, etc.). In that perspective, it is necessary to clearly define, in a transparent and shared manner with interested stakeholders the criteria used to differentiate and categorise subnational governments (OECD, 2017c). Municipal classifications seem to be an interesting approach to recognise and take into account the diversity of municipalities. The assignment of responsibilities can then be tailored to the different categories of municipalities.

Asymmetric arrangements can entail the possibility to delegate some tasks to a higher level of government through ad hoc agreements for a given period (regions). Such arrangements are developing in the OECD (e.g. in France since the law MAPTAM law of 2014 on the modernisation of territorial public action and affirmation of metropolitan areas) (OECD, 2017c).

Asymmetric governance approaches also contain risks, in terms of creating institutional complexity, which were highlighted by the review of Sweden for example (OECD, 2010, 2017). Asymmetric governance approaches may also strengthen or weaken the allegiance of differentially treated communities to the nation state as a whole. What is important to keep in mind is the potential spillover effect that these asymmetric options may have to other regions. Asymmetric approaches may be seen as pilot experiences, which may be generalised on the entire territory once the experiment is considered as successful - as in the case of the regions of Skane and Vastra Gotaland in Sweden for example. Asymmetric status may allow experimental solutions to give more autonomy to specific territories; that can allow a better match between policies and local needs; without going through radical administrative or constitutional reforms. 


\section{Box 10. Asymmetric decentralisation: defining differentiated competences for different municipalities: the cases of Colombia, Denmark and Czech Republic}

In Colombia, capacities vary greatly across jurisdictions. To address this challenge, Colombia has set up a system of certification of municipalities, entailing differentiated competencies. To perform central government delegated functions in the areas of education, health, water and sanitation, municipalities must be certified. In the uncertified municipalities, the department is responsible for these competences.

Colombia is currently considering a new reform to differentiate competencies according to the degree of capacities. The new "Differentiated Competences National Program" included in the 2014-2018 National Development Plan goes further to respond to the disparities among the capacities of subnational governments by providing the possibility of allocating more responsibilities to the more qualified ones. It also envisions alleviating some administrative requirements (e.g. reporting) as today, small municipalities have roughly the same obligations as the large ones, which can be a real burden for them.

The National Planning Department (DNP) has defined general and specific criteria linked to financial, technical and institutional capacities of Colombian municipalities. General criteria assess the institutional capacities of local actors independently of the competence to be delegated (including the provision of basic services, generation of own resources, accomplishing goals of development planning, appropriate use of financial resources, financial solvency and respect of fiscal procedures). For a competence to be devolved, the municipality needs to comply at the same time with specific criteria defined by the national authority that will delegate the competence. Following these two steps of multi-criteria analysis, the DNP identified 131 municipalities that could assume functions currently delivered by the central level.

Sectors that could be more efficiently managed at the municipal level were identified. These include protection and reinsertion of victims, transport (tertiary roads), early childhood, and agricultural and rural development. The priorities will be to delegate competencies for victims’ rights, land registries and transport (tertiary roads).

The municipality has to ask for the delegation of a specific competence. The transfer depends largely on the political will of the local government in taking on additional responsibilities, as devolution is not encouraged by any financial incentive beyond the transfer of the corresponding budget to the municipality. The request is then analysed by the sectoral ministry involved, which may be resistant to give up part of its prerogatives. The first delegation underway is the multi-purpose land registry in the municipality of Barranquilla.

In Denmark, between 2012 and 2015, nine local municipalities in Denmark were granted exemptions from government rules and documentation requirements in order to test new ways of carrying out their tasks, in a policy experiment known as the "Free Municipality” initiative. The main focus has been on simplification, innovation, quality and a more inclusive approach to the individual citizen, with many of the experiments focusing on employment. The Free Municipality experiment is currently being evaluated, in order to form the basis for potential future legislation on debureaucratisation for all municipalities. The concept of Free Municipalities continues in an adjusted form until 2019, and is extended to more municipalities.

In Czech Republic, in the process of decentralisation, the responsibilities of the 76 abolished state "districts" to the municipalities were largely passed on to 205 "municipalities with extended powers" (ORP) in 2003. These municipalities perform central government delegated functions on behalf of smaller surrounding municipalities 
such as child protection and issuing passports. These functions are associated with additional funding. Smaller municipalities can also delegate additional functions to the ORP that they do not want to provide, or cannot provide because of their lack of capacities.

Source: OECD (2017c), OECD (2016d), Making the most of public investment in Colombia; OECD (2017b), Monitoring Review of Sweden; OECD (2016f), Economic Survey of the Czech Republic.

\section{d) Upscaling}

The question of scale is recurrent in Territorial Reviews. Inter-municipal co-operation and up-scaling/mergers can lessen some of the challenges of municipal capacity when local governments are small (see next section).

\section{e) The right data, for the right diagnosis}

For the central government to be able to provide support, the right diagnosis of the different challenges needs to be in place. Territorial Reviews highlight that monitoring and data collection are often lacking, and few countries have rigorous systems for evaluating multilevel governance reforms (among them Norway, Italy, or Australia). Few countries have done systematic assessment of the subnational capacity challenges and the way they vary across places. Not all the capacities can be strengthened at the same time and some capacities may need to be strengthened before than others. It is therefore critical to identify binding constraints, appropriate remedies, and the proper sequence of reforms (OECD, 2013).

Colombia is the example of a country which has developed an innovative system to measure institutional capacity in municipalities, which allows a measurement of the performance of municipalities along four dimensions: effectiveness, efficiency, compliance with legal requirements, and management. Indexes are published on a yearly basis, contributing to enhance accountability with citizens (OECD, 2016).

\section{f) Complementary reforms under-estimated}

Decentralisation and multi-level governance reforms can only really be carried out with success if they are closely linked to other reforms such as the need to improve the governance of land use and give more authority to subnational governments for the later, the clarification in the regulatory framework or the reinforcement of human capacities both quantitatively and qualitatively. For example, unless there is adequate scope for geographic or functional mobility of civil servants, increased devolution of public services may result in a deterioration of the quality of the services in certain jurisdictions (e.g., in rural communities) and/or in increases of overall public employment (IMF, 2009). In fact, allowing some regulatory autonomy and supporting increased participation of subnational jurisdictions in public policy matters may go a long way in addressing decentralisation pressures (IMF, 2009). The question of effective assignment of responsibilities should always be understood in its broader systemic context, in which the different financial, budgeting, regulatory, and public employment systems are mutually dependent. 
Co-ordination challenges and scale issues

Main challenges

\section{$\underline{\text { Scale challenge and co-ordination across jurisdictions }}$}

The insufficient scale of jurisdictions and lack of co-ordination across jurisdictions are key challenges mentioned by a majority of Territorial Reviews:

- In Brazil: the states themselves are large and heterogeneous, and do not often constitute the right scale for implementing regional development policy or other sectoral policies. The municipalities are often too small (70\% of them have less than 20000 inhabitants), and of insufficient size to implement large investments or plan sectoral policies. Smaller municipalities face diseconomies of scale in the delivery of a number of public services such as transport, health care and sanitation, housing and urbanisation, local administration and planning, and education and culture (OECD, 2011).

- In Colombia, competition between municipalities is widespread, yet major social and infrastructure challenges spill over across municipal boundaries and could be better tackled with more co-operation.

- In Chile, urban planning has been hampered by a history of poor co-operation between municipalities and lack of legal status for the joint municipal bodies created to support collaboration. At the regional level, there are problems with the flow of information between national agencies and regional governments. Regions do not have enough institutional capacity to co-ordinate common projects (OECD, 2009).

- In Portugal, the 2008 review recommended to enhance functional collaboration based on potential synergies and common development projects, notably by fostering more flexible inter-municipal collaboration (not necessarily constrained at specific levels).

- In Slovenia, the highly fragmented municipal structure and the number of municipalities raises co-ordination and governance challenges for regional development and public service delivery i.e. many municipalities are too small to provide some public services efficiently. Slovenia appears to lack effective regional co-ordination hubs that bring together issues and actors across sectors to achieve shared objectives (OECD, 2011).

In the 2015 OECD/CoR survey results, co-ordination was perceived as a significant challenge by most SNGs surveyed. More than three-quarters of SNGs reported the absence of a joint investment strategy with neighbouring cities or regions (OECD/CoR, 2015c). Nearly the same percentage of SNGs also considered the lack of incentives including financial - to co-operate across jurisdictions to be a problem.

\section{Central-subnational co-ordination}

Another common finding from the reviews and from the OECD work on multi-level governance is that there are important co-ordination gaps across the national and subnational governments (on information, financing, regulation, etc.) (Charbit and Michalun 2009). Central-local co-ordination is also recognised by the IMF as the one where advanced economies tend to fare the worst for efficient public investment (IMF, 2015). Findings from the OECD-CoR survey confirm that challenges in vertical coordination between SNGs and national governments are prominent (OECD/CoR, 2015c). 


\section{Good practices and lessons}

Increased vertical and horizontal co-operation is a recurrent recommendation from Reviews and from the OECD Recommendation on Effective Public Investment across Levels of Government.

\section{Vertical co-ordination}

If challenges remain numerous, a number of OECD countries - in particular federal countries or Nordic countries - have made progress toward better vertical co-ordination across levels of government. Platforms for vertical co-ordination have been established in several OECD member states, in particular federal countries. Eleven countries in the OECD have put in place structures of co-ordination. Often these are related to environment, infrastructure, transport, technology, and development. In 14 countries, the national government needs to consult subnational governments prior to issuance of new regulations (OECD, 2017).

The recent economic crisis has also spurred investment in both ad hoc and permanent bodies for horizontal and vertical co-ordination in several countries, though in some cases only at the intermediate level. Fiscal Councils and internal stability pacts have been used since the crisis to strengthen multilevel fiscal co-ordination in macroeconomic management; Belgium, Austria, Brazil, Spain, Germany, Portugal, and Italy have all strengthened or expanded these institutions in recent years (OECD, 2017).

Despite their expense and the time needed to establish them, standing commissions and intergovernmental consultation boards that create a permanent conduit for co-operation and communication across parties and levels of government can facilitate reform when the time comes. Creating a culture of co-operation and regular communication is crucial to effective multilevel governance and long-term reform success.

More recent OECD work has shown that the most decentralised countries tend to have more co-ordination mechanisms in place (OECD, 2017). Because federal countries are more likely to have institutions for intergovernmental co-ordination already in place, clearly delineating responsibility for competences is most pressing in unitary countries where shared or overlapping responsibilities are more likely to lack the necessary institutional support for high levels of co-ordination. 
Box 11. Examples of mechanisms of vertical co-ordination

- In Australia, the Council of Australian Governments (COAG) is the main intergovernmental forum for the development and implementation of interjurisdictional policy. It gathers the Australian Prime Minister (chair), Territory Premiers and Chief Ministers and the President of the Australian Local Government Association. The main role of the COAG is to promote policy reforms that need coordinated action by all Australian Governments. Its agenda is broad and focuses on reforms that have a direct impact on well-being.

- In Canada, the federal government is represented in the provinces via structures such as regional federal councils and regional development agencies, whose interests lie not only in representing the federal government's priorities in the provinces but also in conveying provincial preferences to the federal authorities. The result is tripartite agreements (i.e. formal contractual arrangements among federal, provincial, and local authorities) that support the implementation of infrastructure policies.

- In France, territorial strategies are formalised as contractual arrangements across levels of government through state-region planning contracts (contrat de plan État-région) that stipulate co-decision and co-financing of interventions.

- The Local Government Commission in New Zealand is an independent, permanent body for inquiry into local reform created by the Local Government Act in 2002 specifically with the aim of building a relationship across party lines in the context of multilevel governance needs (OECD, 2017).

Source: www.oecd.org/effective-public-investment-toolkit/

\section{Increased inter-municipal co-operation}

Subnational horizontal co-ordination is essential to increase efficiency through economies of scale, and to enhance synergies among policies of neighbouring jurisdictions. Intermunicipal co-operation has been mainstreamed in the European Union and OECD municipal management practices, and so has become more established in recent years. France, the UK, Australia, New Zealand, and Ireland are all countries with robust programmes for managing shared services (OECD, 2017; OECD, 2006). OECD countries have formal horizontal co-ordination mechanisms at the municipal level (OECD, 2017d).

Determining optimal subnational unit size is a context-specific task; it varies not only by region or country, but by policy area, as well. The efficient size differs between waste disposal, schools or hospitals. In Finland, research on scale benefits of expanding the size of local governments found that large municipalities were less efficient at service delivery and the optimal size was between 20000 and 40000 inhabitants (OECD, 2017a; Moisio, Loikkanen, and Oulasvirta, 2010). Yet in Japan, unit costs of public services bottomed out at about 120000 inhabitants and increased at both higher and lower municipal sizes (OECD, 2017; Hayashi, 2002). In general the optimal range for efficient public service provision appears to be between 20000 and 250000 people (OECD, 2017: 52; McKinlay Douglas Limited, 2006; Holzer, et al. 2009), but this is a vast range. The same reform may also impact different units differently.

Municipal mergers may be considered as an effective means in larger conurbations with a high degree of municipal fragmentation, but ineffective when the size of municipalities is already large or in remote areas where service delivery is largely determined by 
geography. Often, efficiency gains can be made without abolishing tiers or merging municipalities (OECD, 2017). In Spain, joint municipal management of waste collection produced significant economic benefits, with an estimated $20 \%$ savings in municipalities with fewer than 20000 inhabitants. Shared service agreements between councils in England have saved GBP 462 million through September 2015 (OECD, 2017a).

In the Netherlands, the increasing number of municipal responsibilities has prompted discussions on amalgamating and ensuring greater co-operation between municipalities in order to increase their capacity to deliver these policies. The decentralisation reform has reignited the debate on the right size for municipalities, and has become the main driver of the territorial reorganisation. Municipalities, especially the smaller ones, will face major challenges performing their new mandatory social functions adequately. Small municipalities may not have the capacity to deal with these new responsibilities, in particular the managerial, administrative and financial capacities.

\section{Guidelines for policy-makers}

Decentralisation has increased in OECD countries and in the world. Its outcomes much depend on the way the process is designed and implemented, on adequate subnational capacity, and on the quality of multi-level governance, including efficient co-ordination mechanisms across levels of government.

While OECD countries seem to have made progress on the co-ordination front, the bigger challenges seem to be on the clarity of responsibilities and functions assigned to the different levels, and the capacities to handle them. The challenges are more acute in developing contexts, but it is also surprising to see that a large number of OECD countries mention challenges in this field as well. Overall, it should be remembered that decentralisation reforms tend to take a considerable amount of time and assignment of responsibilities need to be periodically reviewed.

Ten guiding principles, which apply to all types of countries, have been identified. They are set out below:

\section{Ten guidelines for effective assignment of responsibilities conducive to regional and local development}

\section{1) Clarify the sector responsibilities assigned to different government levels}

- While inevitably most responsibilities are shared across levels of government and spending responsibilities overlap in many policy areas, it is crucial to ensure adequate clarity of the role of each level of government in the different policy areas to avoid duplication, waste, and loss of accountability. Clarity and balanced assignment are more important pre-requisites than determining the government level to which policy areas should be assigned (OECD, 2016b).

- Clear assignment is critical for accountability, monitoring and effectiveness of investment and service delivery policies. The more a responsibility area is shared across different government levels, the greater clarity is needed to reduce duplication and overlaps.

- Clarity does not mean that shared responsibilities should be avoided, as this is by definition impossible, even in federal contexts. It means that the way responsibilities are 
shared should be explicit, mutually understood and clear for all actors, including citizens.

- Clarity in the assignment should particularly be watched in unitary countries with three tiers of government, particularly for the intermediate level.

- Since multi-level governance systems are constantly evolving, a periodic review of jurisdictional assignments should be made to ensure flexibility in the system (Shah, 2007).

- It is also critical to have clarity in the responsibilities assigned to deconcentrated state administrations in territories, vs. decentralised subnational governments, as too often the arrangements are somewhat opaque.

\section{2) Clarify the functions assigned to different government levels}

- Equally important is the clarity in the different functions that are assigned, within policy areas - financing, regulating, implementing, or monitoring. Where concurrent sectoral responsibilities exist, responsibilities for regulation, financing, and delivery and implementation should be allocated explicitly across the different levels of government and 'grey areas' in the way functions are assigned should be avoided.

\section{3) Ensure balance in the way different responsibilities and functions are decentralised}

- It is important to ensure balance in the way various policy functions are decentralised, to allow for complementarities across decentralised policies and integrated policy packages, for effective territorial development approaches (OECD 2016a, OECD, 2014). Balanced decentralisation - i.e. when the various policy functions are decentralised to a similar extent - is conducive to growth (OECD, 2016a).

- An effective regional or local development strategy requires a balance in the way policy areas are decentralised. If decentralisation only takes place in 2 or 3 policy areas (like health or housing) in an unbalanced way vis-à-vis other policy areas, this will prevent subnational governments from designing integrated regional and local development strategies. For example, OECD analyses point out that infrastructure investment alone has little impact on regional growth unless it is associated with human capital and innovation (OECD, 2009).

- Within each function, the responsibilities should be balanced. For example, it is not recommended for one level to have an exclusive focus on operating functions. Within functions, if a level of government is involved in financing, it is recommended to have a balanced focus on operating vs. capital expenditure, rather than a single focus on operating expenditure only. 
4) Align subnational responsibilities and revenues and enhance subnational capacity to manage their resources The responsibilities assigned to SNGs should be aligned with their revenues. The OECD, the IMF and the World Bank all converge on the fact that control over a portion of subnational resources is critical to promoting accountability of SNGs. For decentralisation arrangements as a whole, a better alignment between control of financial resources and responsibility for spending is key (OECD, 2016b).

- Subnational governments need own-source revenues beyond shared tax revenues - and they need to develop other sources of revenues to have a balanced basket of revenues. Higher own-tax share may contribute to make subnational governments more efficient and accountable and help mobilise resources at the state/region and local level (OECD, 2016g).

- Non-earmarked grants are usually more efficient funding instruments than earmarked grants (Bergvall et al., 2006). Nevertheless, there are some cases where earmarked grants can be used in an efficient way. The formulae for determining central government transfers, grants, and earmarked funds from the centre to lower levels of government should be transparent and non-discretionary.

- Equalisation transfers should be put in place, but are not sufficient to prevent from increasing regional inequalities. Inclusive territorial development may imply in particular: (i) pro-active regional development policies from the different levels of government, including the national level; (ii) asymmetric decentralisation arrangements; (iii) a consistent long-term focus on subnational capacity building.

\section{5) Capacity building for SNGs must actively supported with resources from the centre}

- More responsibilities at the subnational level need to be complemented with the human resources capable of managing them, and too often this dimension is under-estimated. Subnational governments should have the responsibility and be able to monitor employee numbers, costs and competencies.

- Capacity development at the subnational level, particularly in poor or very small municipalities, must be actively supported with resources from the centre, and require long-term commitment. Capacity building must be tied into equalisation, public investment and regional development policies.

\section{6) Build adequate co-ordination mechanisms across levels of government}

- Since most responsibilities are shared, it is crucial to establish governance mechanisms to manage those joint responsibilities. Creating a culture of co-operation and regular communication is crucial to effective multilevel governance and long-term reform success. Such tools for vertical co-ordination include for example platforms of dialogue, fiscal councils, contractual arrangements, standing commissions and intergovernmental consultation boards.

\section{7) Support cross-jurisdictional co-operation through specific incentives}

- Subnational horizontal co-ordination is essential to increase efficiency through economies of scale. It should be supported through specific financial incentives or 
governance arrangements. Determining optimal subnational unit size is a contextspecific task; it varies not only by region or country, but by policy area, as well.

- Municipal mergers are considered as an effective means in larger conurbations, but ineffective in remote areas where service delivery is largely determined by geography. Often, efficiency gains can be made without abolishing tiers or merging municipalities, in particular by strengthening inter-municipal co-operation.

\section{8) Allow for pilot experiences in specific places and asymmetric arrangements}

- Allow the possibility for asymmetric decentralisation, when differentiated sets of responsibilities are given to different types of regions/cities, based on population size, rural/urban classification and fiscal capacity criteria. Large cities for example may have responsibilities for some services which are provided directly by the centre in other areas.

- Ensure flexibility in implementation, allowing for pilot experiences in specific places/regions - and permanent adjustments through learning-by-doing.

\section{9) Focus on the complementary reforms}

- Effective decentralisation requires complementary reforms in the governance of landuse, citizen participation and innovative public service delivery and governance. Promoting citizens' engagement in policy-making should go hand in hand with decentralisation reforms.

\section{0) Strengthen monitoring systems and data collection}

- Monitoring and data collection need to be carried out to monitor the effectiveness of subnational public service delivery and investments. Most countries need to develop effective monitoring systems of subnational spending and outcomes. 


\section{References}

Allain-Dupré et al (2017), "Subnational infrastructure investment in OECD countries: trends and key governance levers", OECD Regional Development Working Papers, OECD Publishing, Paris, forthcoming.

Bergvall et al (2006)., Intergovernmental transfers and decentralised public spending, https://www.oecd.org/tax/federalism/37388377.pdf

Blöchliger, H. and C. Vammalle (2012), Reforming Fiscal Federalism and Local Government: Beyond the Zero-Sum Game, OECD Publishing, Paris. http://dx.doi.org/10.1787/9789264119970-en.

Chapman Osterkatz, S. (2013), "Commitment, Capacity, and Community: the Politics of Multilevel Health Reform in Spain and Brazil.” Doctoral dissertation, University of North Carolina at Chapel Hill.

Charbit, C. and M. Michalun (2009), "Mind the gaps: Managing Mutual Dependence in Relations among Levels of Government", OECD Working Papers on Public Governance, No. 14, OECD Publishing, Paris.

Chatry, I. and Hulbert, C. (2017), Multi-level governance reforms: Overview of OECD country experiences, OECD Publishing, Paris.

Council of Europe (1998), Regionalisation and Its Effects on Local Self-Government: Local and Regional Authorities in Europe. No. 64. Strasbourg: Council of Europe Publishing.

Cour des Comptes (2017), www.ccomptes.fr/sites/default/files/2017-06/20170629-RSPFP.pdf

de Mello, L. and Tovar Jalle, J. (2018), “The Global Crisis and Intergovernmental Relations: Revisiting the Centralisation-Decentralisation Debate Ten Years On”, GEN Working Paper A 2018 - 3, http://infogen.webs.uvigo.es/WP/WP1803.pdf

DCLG/Department for Communities and Local Government (2006), The Free Communes Experiments: lessons for policy in England, S. Martin, S. Lux from Centre for Local and Regional Government Research Cardiff University and J. Loughlin from the School of European Studies Cardiff University, June.

EBRD/World Bank (2000), Achievements and Challenges of Fiscal decentralisation, Lessons from Mexico, Washington, DC (link).

Falleti, Tulia, (2010). Decentralization and Subnational Politics in Latin America. New York: Cambridge University Press. 
Gervasoni, Carlos (2010). "Measuring Variance in Subnational Regimes: Re- sults from an Expert-Based Operationalization of Democracy in the Argentine Provinces.” Journal of Politics in Latin America 2(2)13-52.

Giraudy, Agustina, (2010), "The politics of subnational undemocratic regime reproduction in Argentina and Mexico." Journal of Politics in Latin America 2 (2010): 53-84.

Gurgur, Tugrul, and Anwar Shah (2005), Localization and corruption: panacea or pandora's box?, Vol. 3486. World Bank Publications, World Bank, Washington, DC.

Holzer et al. (2009), Literature Review and Analysis Related to Optimal Municipal Size and Efficiency, Local Unit Alignment, Reorganization, and Consolidation Commission (LUARCC), School of Public Affairs and Administration (SPAA), Rutgers University,

Hooghe, Liesbet, Gary Marks, and Arjan H. Schakel (2010), The Rise of Regional Authority. A Comparative Study of 42 Democracies. London: Routledge.

Hooghe, Liesbet, Gary Marks, Arjan H. Schakel, Sara Niedzwiecki, Sandra Chapman Osterkatz, Sarah Shair-Rosenfield (2016), Measuring Regional Authority: A Postfunctionalist Theory of Governance, Volume 1. Oxford: Oxford University Press.

Hooghe, Liesbet and Gary Marks with Arjan H. Schakel, Sara Niedzwiecki, Sandra Chapman Osterkatz, Sarah Shair-Rosenfield (2016), Community, Scale, and Regional Governance: A Postfunctionalist Theory of Governance, Volume 2. Oxford: Oxford University Press.

Ivanyna, Maksym, and Anwar Shah (2011), "Decentralization and corruption: new cross-country evidence." Environment and Planning C: Government and Policy 29.2 (2011): 344-362.

Ivanyna and Shah (2014), "How Close Is Your Government to Its People? Worldwide Indicators on Localization and Decentralization.” Economics: The Open-Access, Open-Assessment E-Journal, 8 (2014-3): 1—61. http://dx.doi.org/10.5018/economics-ejournal.ja.2014-3

Joumard, Isabella, and Per M. Kongsrud (2003), “Fiscal Relations Across Government Levels.” OECD Economics Department Working Papers \#375. Paris: Organization for Economic Cooperation and Development.

McKinlay Douglas Limited (2006), Local government structure and efficiency, report prepared for Local Government New Zealand, available at: www.mdl.co.nz/site/mckinley/files/Local\%20Government\%20Structure\%20and\%20Efficiency.pdf

McKinley, P. (1998): "Local Government Reform: What Was Ordered and What Has Been Delivered”, Local Government New Zealand, Wellington.

Moisio, A., H.A. Loikkanen and L. Oulasvirta (2010), "Public services at the local level: The Finnish way”, Policy Report 2, Government Institute for Economic Research, Helsinki.

Moreno, Luis (2006), "Federalization and ethnoterritorial concurrence in Spain" Instituto de Estudios Sociales Avanzados (CSIC) Working Paper 96-06. http://ipp.csic.es/sites/default/files/content/workpaper/1996/dt-9606_1.pdf 
Navruzov, Yury (2001), "Local government in Ukraine." Developing New Rules in the Old Environment (2001): 111-159.

OECD (2001), OECD Territorial Reviews: Italy 2001, OECD Publishing, Paris.

OECD/LEED (2003), Managing Decentralisation: a new role for labour market policy, Paris.

OECD (2005), OECD Territorial Reviews: Japan 2005, OECD Publishing, Paris.

OECD (2006), OECD Territorial Reviews: France 2006, OECD Publishing, Paris.

OECD (2008a), OECD Territorial Reviews: Poland 2008, OECD Publishing, Paris.

OECD (2008b), OECD Territorial Reviews: Portugal 2008, OECD Publishing, Paris.

OECD (2008c), OECD Territorial Reviews: Norway 2008, OECD Publishing, Paris.

OECD (2009), OECD Territorial Reviews: Chile 2009, OECD Publishing, Paris.

OECD (2010), OECD Territorial Reviews: Sweden 2010, OECD Publishing, Paris.

OECD (2011), OECD Territorial Reviews: Switzerland 2011, OECD Publishing. http://dx.doi.org/10.1787/9789264092723-en

OECD (2011b), OECD Territorial Reviews: Slovenia 2011, OECD Publishing. http://dx.doi.org/10.1787/9789264120570-en

OECD (2011c), Making the Most of Public Investment in a Tight Fiscal Environment: Multi-level Governance Lessons from the Crisis, OECD Publishing, Paris.

http://dx.doi.org/10.1787/9789264114470-en

OECD (2013a), OECD Territorial Reviews: Brazil 2013, OECD Publishing. http://dx.doi.org/10.1787/9789264123229-en

OECD (2013b), Investing Together: Working Effectively across Levels of Government, OECD Publishing. http://dx.doi.org/10.1787/9789264197022-en

OECD (2013c), OECD Territorial Reviews: Ukraine 2013, OECD Publishing. http://dx.doi.org/10.1787/9789264204836-en

OECD (2014a), OECD Territorial Reviews: Colombia 2014, OECD Publishing. http://dx.doi.org/10.1787/9789264224551-en

OECD (2014b), OECD Territorial Reviews: Netherlands 2014, OECD Publishing. http://dx.doi.org/10.1787/9789264209527-en

OECD (2015a), Governing the City, OECD Publishing. http://dx.doi.org/10.1787/9789264226500-en

OECD (2015b), The Metropolitan Century: Understanding Urbanisation and its Consequences, OECD Publishing. http://dx.doi.org/10.1787/9789264228733-en 
OECD (2015c), Infrastructure planning and investment across levels of government, results of the OECD-CoR survey, https://portal.cor.europa.eu/europe2020/pub/Documents/oecd-corjointreport.pdf

OECD (2016a), Decentralisation and quality of public finance: Intermediate Report, COM/CTPA/ECO/GOV(2016)1

OECD (2016b), Assigning responsibilities across government levels, Note by the secretariat COM/CTPA/ECO/GOV(2016)3

OECD (2016c), OECD Territorial Reviews: Japan 2016, OECD Publishing, Paris. http://dx.doi.org/10.1787/9789264250543-en

OECD (2016d), OECD Regions at a Glance 2016, OECD Publishing, Paris http://dx.doi.org/10.1787/reg_glance-2016-en

OECD (2016e), Overview on Indicators of Co-ordination of Public Investment for Regional Development, OECD Publishing, Paris.

OECD (2016f), Making the Most of Public Investment in Colombia: Working Effectively across Levels of Government, OECD Publishing, Paris.

OECD/KIPF (2016g), Fiscal Federalism 2016: Making Decentralisation Work, OECD Publishing, Paris.

OECD/UCLG (2016h), Subnational Governments around the world: Structure and finance.

OECD (2016i), OECD Territorial Reviews: Peru 2016, OECD Publishing, Paris. http://dx.doi.org/10.1787/9789264262904-en

OECD (2017a), Multi-level Governance Reforms: Overview of OECD Country Experiences, OECD Publishing, Paris.

OECD (2017b), Making Decentralisation Work in Chile: Towards Strong Municipalities, OECD Publishing, Paris.

OECD (2017c), Subnational governments in the OECD: Key data, OECD Publishing, Paris.

OECD (2017d), Multi-level Governance Indicators, working document.

OECD (2017e), Governance of Land Use, OECD Publishing, Paris

Rodríguez-Pose, Andrés (2008), Decentralisation and local and regional development, CAF DOCUMENTOS DE TRABAJO Nº 2008/04 August, 2008 https://www.caf.com/media/3897/200804Rodr\%C3\%ADguez-Pose.pdf

Rodríguez-Pose, Andrés and Anne Kroijer (2009), Fiscal Decentralization and Economic Growth in Central and Eastern Europe, in Growth and Change - A journal of Urban and Regional policy, https://doi.org/10.1111/j.1468-2257.2009.00488.x

Shah, A. (2007), The Practice of Fiscal Federalism: Comparative Perspectives , McGill-Queen's University Press 
Smith, Christine (2006). Insights from fiscal federalism literature Chapter 13. Quantifying the Costs and Benefits of Change: Towards A Methodology http://press-

files.anu.edu.au/downloads/press/p52401/mobile/ch13s06.html

Sugiyama, Natasha Borges, and Wendy Hunter. "Whither Clientelism? Good Governance and Brazil's Bolsa Família Program." Comparative Politics 46.1 (2013): 43-62.

Ter-Minassian, Fiscal Federalism in Theory and Practice, IMF, Washington DC, 1997

Tompson, W. (2009), The Political Economy of Reform: Lessons from Pensions, Product Markets and Labour Markets in Ten OECD Countries, OECD Publishing, Paris. http://dx.doi.org/10.1787/9789264073111-en.

Zuber, Christina Isabel. (2008), Asymmetry—Stabilising Multinational States? A Cross- Regional Study of the Effects of Asymmetrical Autonomy Levels in the Russian Federation. Magisterarbeit. Philosophische Fakultät, Universität zu Köln. 
Annexe A.

LESSONS FROM TERRITORIAL REVIEWS ${ }^{15}$

15 This table is a compilation of information in the original Territorial Review, and thus the examples, challenges and recommendations reflect what was in place at the time of research and writing. Reforms or changes may have been undertaken since the time of publication, and these are not reflected here. 


\begin{tabular}{|c|c|c|}
\hline $\begin{array}{c}\text { Territorial } \\
\text { Review (MLG } \\
\text { chapters) }\end{array}$ & Examples of assignment issues & $\begin{array}{l}\text { Selected examples of recommendations linked to the assignment } \\
\text { of responsibilities }\end{array}$ \\
\hline $\begin{array}{c}\text { Territorial } \\
\text { Review of } \\
\text { Brazil (2013) }\end{array}$ & $\begin{array}{l}\text { The Constitution gives municipalities the status of federal entities, at the same level as the states. } \\
\text { This special status implies that neither the federal government nor the states can compel or prohibit } \\
\text { actions by municipalities. In addition, municipalities enjoy a large share of tax revenues, and have } \\
\text { important spending responsibilities in key areas such as education and health. } \\
\text { Lack of clear division of responsibilities in a number of areas, such as health care, education, social } \\
\text { security, welfare, agriculture, and food distribution, environmental protection, sanitation and housing, } \\
\text { etc. With few exceptions (e.g. defence), responsibilities are shared, with frequent overlaps of } \\
\text { responsibilities across level of government. } \\
\text { Problem of scale: the states themselves are large and heterogeneous, and do not often constitute the } \\
\text { right scale for implementing regional development policy or other sectoral policies. The municipalities } \\
\text { are often too small ( } 70 \% \text { of them have less than } 20 \text { 000 inhabitants), and of insufficient size to } \\
\text { implement large investments or plan sectoral policies. Smaller municipalities face diseconomies of } \\
\text { scale in the delivery of a number of public services such as transport, health care and sanitation, } \\
\text { housing and urbanisation, local administration and planning, and education and culture. } \\
\text { Insufficient capacity is considered as one of the bottlenecks for the implementation of policies in } \\
\text { lagging regions, for the insufficient level of public investment and for the difficulties in generating } \\
\text { endogenous growth in the regions? }\end{array}$ & $\begin{array}{l}\text { - The administrative map of Brazil at the intermediary level between } \\
\text { municipalities and states needs to be simplified and unified. } \\
\text { - An institutional streamlining is required to improve the co-ordination } \\
\text { among levels of government. } \\
\text { - Horizontal co-ordination among subnational governments should be } \\
\text { defined. } \\
\text { - Horizontal co-ordination between sectorial ministries at the federal level (i.e } \\
\text { breaking out of policy silos) is needed, as is co-ordination between levels o } \\
\text { government, whether federal, state or municipal. This can make } \\
\text { implementation more coherent, because it is typically shared between diffe } \\
\text { levels of government. It also requires co-ordination between local actors } \\
\text { and municipalities. } \\
\text { Building institutional and administrative capacity at subnational leve } \\
\text { and increasing civil society participation in public co-ordination. }\end{array}$ \\
\hline Chile (2009) & $\begin{array}{l}\text { Competence allocation among Chile's municipalities is homogenous: i.e. all municipalities regardless } \\
\text { of size are responsible for delivering the same set of public services. A high degree of variation in } \\
\text { municipal capacity through the territory makes uniform service delivery unrealistic and often } \\
\text { impossible. At the local level, most municipalities currently have neither the resources nor the } \\
\text { incentive to invest in local economic development initiatives. Incentives are needed to strengthen } \\
\text { both the capacities and resources of municipalities (especially those of the least developed) to } \\
\text { engage in local economic development. } \\
\text { Regional governments do not have enough institutional strength to manage and co-ordinate a } \\
\text { common strategy for the region (that draws the various agencies and actors in the region). An } \\
\text { ongoing decentralization process (initiated in 2013) plans to modernize and strengthen municipal } \\
\text { functions and transfer new competencies to the new self-governing regions in three areas: economic } \\
\text { development, social development, infrastructure and housing. } \\
\text { Lack of metropolitan governance and fragmentation of the metropolitan areas into different }\end{array}$ & $\begin{array}{l}\text { - Give subnational governments (SNGs) greater role in shaping thei } \\
\text { development responsibilities (i.e. set a regionally based strategic agenda } \\
\text { reinforce regional/urban development strategies, etc.). } \\
\text { - The assignment of responsibilities to municipalities should be } \\
\text { accompanied by a concomitant allocation of the resources } \\
\text { competences and organisational flexibility needed to carry them ou } \\
\text { efficiently. } \\
\text { - Introduce mechanism to address the misalignment between resources } \\
\text { and competences at the local level. These can include creating } \\
\text { incentives for horizontal co-operation in service delivery; transferring select } \\
\text { competences to a higher level of government; create different categories o } \\
\text { "tiers" of municipalities and ascribing competences based on the } \\
\text { municipality's level, with smaller authorities having fewer high-cos }\end{array}$ \\
\hline
\end{tabular}




\begin{tabular}{|c|c|c|}
\hline $\begin{array}{c}\text { Territorial } \\
\text { Review (MLG } \\
\text { chapters) }\end{array}$ & Examples of assignment issues & $\begin{array}{l}\text { Selected examples of recommendations linked to the assignment } \\
\text { of responsibilities }\end{array}$ \\
\hline & $\begin{array}{l}\text { municipalities, i.e. Greater Santiago is composed of } 35 \text { autonomous municipalities (comunas), } \\
\text { affecting the co-ordination in the delivery and management of key public urban services (i.e. public } \\
\text { transport). } \\
\text { The lack of flexibility to adapt the organisational structure of municipalities to local characteristics and } \\
\text { demands has also hindered capacity building at the local level. }\end{array}$ & $\begin{array}{l}\text { responsibilities than larger ones. } \\
\text { A co-ordinated local governance structure is required in big cities for } \\
\text { ensuring that different sector policies implemented in the metropolitan area } \\
\text { are correctly integrated. }\end{array}$ \\
\hline $\begin{array}{l}\text { Chile (MLG } \\
\text { Review, 2017) }\end{array}$ & $\begin{array}{l}\text { In formal terms, the areas of municipal intervention are vast. According to article } 1 \text { of the LOCMUN } \\
\text { No. 18.695, their purpose is "to meet the needs of the local community and ensure their participation } \\
\text { in the economic, social and cultural progress of the respective comunas". The LOCMUN defines six } \\
\text { exclusive and thirteen non-exclusive/shared functions for municipal intervention. } \\
\text { Among the shared competences are two major responsibilities, transferred in the 1980s and which } \\
\text { are particularly sensitive, politically, socially and economically: primary and secondary education and } \\
\text { basic health services. Despite being "decentralisation laws", these regulations leave little autonomy to } \\
\text { municipalities whose functions are to implement national policies. These functions are better defined } \\
\text { as deconcentrated or delegated functions than truly decentralised functions. The financing of these } \\
\text { two responsibilities comes from central administration transfers based on subsidies for benefits } \\
\text { granted and coming from the ministries in charge. } \\
\text { In the end, municipalities have a very broad spectrum of functions. However, in practice, } \\
\text { municipalities are faced with numerous technical, managerial and financial constraints and limitations, } \\
\text { especially in rural areas, that reduce the real level of municipal intervention and autonomy. In some } \\
\text { areas, municipalities cannot intervene despite the huge needs and municipal legitimacy to do so. } \\
\text { Regional governments do not have enough institutional strength to manage and co-ordinate a } \\
\text { common strategy for the region (that draws the various agencies and actors in the region). An } \\
\text { ongoing decentralization process (initiated in 2013) plans to modernize and strengthen municipal } \\
\text { functions and transfer new competencies to the new self-governing regions in three areas: economic } \\
\text { development, social development, infrastructure and housing. }\end{array}$ & $\begin{array}{l}\text { - Reducing the number and scope of shared competences and increase } \\
\text { exclusive responsibilities. } \\
\text { - Setting up a work group to examine more precisely the list of } \\
\text { responsibilities, which could be carried out exclusively by municipalities. } \\
\text { They should be related to local economic and social development } \\
\text { ("territorial-based"). This work should be carried out in the framework of the } \\
\text { overall discussion about the assignment of responsibilities across levels of } \\
\text { governments. } \\
\text { - Reconsidering the functions carried out by municipalities within the area of } \\
\text { some shared competences (e.g. by distinguishing financing functions). This } \\
\text { reflection should be conducted in a co-ordinated manner with sector } \\
\text { ministeries to take into consideration current reforms, in particular the "New } \\
\text { Public Education" reform. } \\
\text { Assigning different competences based on the different categories of } \\
\text { municipalities. Large capable municipalities would have higher budget } \\
\text { responsibilities than smaller ones. Less capable municipalities should be } \\
\text { supported by specific schemes in order to avoid recreating inequalities. } \\
\text { Chile could start by experimenting with asymmetric decentralisation through } \\
\text { pilot projects to meet the needs' of more place-based policies as a way to } \\
\text { ensure a gradual institutional change and 'learning-by-doing'. Flexibility } \\
\text { could be promoted in the framework of the education reform. }\end{array}$ \\
\hline $\begin{array}{l}\text { Colombia } \\
\text { (2014) }\end{array}$ & $\begin{array}{l}\text { The majority of the competences attributed to municipalities are shared with departments or the } \\
\text { central administration. Education }(36 \%) \text { is the top budget item for the subnational public sector, then } \\
\text { health }(20 \%) \text {, general public services }(15 \%) \text { and economic affairs, i.e. mainly transport (11\%), social } \\
\text { protection }(5 \%) \text { and housing and community amenities }(5 \%) \text {. }\end{array}$ & $\begin{array}{l}\text { - Targets in terms of reallocation of responsibilities must be well } \\
\text { defined as must the means for reaching them. The responsibilities of the } \\
\text { different levels of government must be clearly presented. In Colombia, as in } \\
\text { many OECD countries, concurrent responsibilities across different levels of }\end{array}$ \\
\hline
\end{tabular}




\begin{tabular}{|c|c|c|}
\hline $\begin{array}{l}\text { Territorial } \\
\text { Review (MLG } \\
\text { chapters) }\end{array}$ & Examples of assignment issues & $\begin{array}{l}\text { Selected examples of recommendations linked to the assignment } \\
\text { of responsibilities }\end{array}$ \\
\hline & $\begin{array}{l}\text { The cumbersome allocation of responsibilities across different levels of government makes the } \\
\text { funding system complex, and it is difficult to assess if a specific service, whose management } \\
\text { corresponds to different layers of the administration, is appropriately financed. } \\
\text { Inter-jurisdictional competition is obstacle to fostering horizontal collaboration at the local level in } \\
\text { many places. Competition between municipalities often tends to trump collaboration incentives, as } \\
\text { municipalities compete to obtain funding from higher levels of government. Where indivisible assets } \\
\text { like schools and hospitals are concerned, collaboration can be harder still. } \\
\text { Subnational governments have too few incentives, capacities and tools to co-ordinate among } \\
\text { themselves. }\end{array}$ & $\begin{array}{l}\text { government create ambiguity, leading to inefficiencies in the public } \\
\text { services' provisions. } \\
\text { - To clearly define the role and responsibilities of each level of } \\
\text { government is a crucial issue in Colombia, as many sub-national authorities } \\
\text { reported doubts about their own responsibilities in important areas such as } \\
\text { health or education, where municipalities and departments have share } \\
\text { responsibilities. }\end{array}$ \\
\hline $\begin{array}{l}\text { Colombia } \\
\text { (MLG Review, } \\
\text { 2016) }\end{array}$ & $\begin{array}{l}\text { While spending autonomy is limited, Colombia is among the most unitary decentralised countries in } \\
\text { terms of subnational public spending in Latin America. } \\
\text { Challenges for Colombia to sustain public investment lie essentially on the governance framework. } \\
\text { Efforts to further support financing should be accompanied by a more systemic approach to the } \\
\text { governance of public investment. Colombia needs to reduce the overall fragmentation of the system. } \\
\text { Supporting more strategic investment requires greater links between planning and budgeting, } \\
\text { incentives to support horizontal co-operation across jurisdictions, in particular to strengthen functional } \\
\text { urban areas, relatively small in Colombia. } \\
\text { Overall, subnational governments have the appropriate mandates and tools, but the low level of } \\
\text { capacities in more than two thirds of Colombian jurisdictions is probably the most important } \\
\text { bottleneck for effective public investment. }\end{array}$ & $\begin{array}{l}\text { - } \text { Given that most transfers are strictly earmarked, there is room to introduce } \\
\text { some flexibility in the transfer' system, notably to re-allocate unspent funds. } \\
\text { Enhance the capacity of SNGs to raise own-source revenues, through: } \\
\text { (i) continuing efforts to update and modernize the cadastral and land } \\
\text { registries in order to improve the municipal property tax performance; (ii) } \\
\text { streamlining the portfolio of taxes levied by departments and municipalities } \\
\text { and promote shared taxation between the central and subnational } \\
\text { governments; (iii) reducing the number of earmarked taxes; (iv) allowing } \\
\text { instruments such as congestion charges or tolls; (v) promoting more } \\
\text { flexibility in terms of user tariffs and local fees and optimise income from } \\
\text { properties (rents, dividends). } \\
\text { Provide financial incentives to support horizontal associations across } \\
\text { municipalities and departments, for example through matching grants/co- } \\
\text { financing projects between the national government and subnational } \\
\text { associations. Further supporting horizontal co-operation across jurisdictions } \\
\text { is particularly important at the metropolitan level, notably for Bogotá, Cali or } \\
\text { Cartagena, which are not yet structured as metropolitan areas. } \\
\text { Support asymmetric decentralisation in two directions (i) devolving } \\
\text { additional competences to most capable SNGs as planned in the } \\
\text { programme currently in place; (ii) simplify reporting mechanisms of weaker } \\
\text { SNGs to alleviate the administrative burden. Colombia could take }\end{array}$ \\
\hline
\end{tabular}




\section{Territorial}

Review (MLG

chapters)

Examples of assignment issues

Selected examples of recommendations linked to the assignment of responsibilities

advantage of pilot experiences in the devolution of competencies as a way to ensure a gradual institutional change and learning by-doing.

- A systemic approach to capacity building for public investment. Colombia should identify obsolete or overlapped procedures that could be modernised and consolidate financial monitoring reports separated by funding source to reduce administrative burden at the local level.

- Colombia should put more emphasis on the design and selection of projects. The General Adjusted Methodology, currently unevenly used by municipalities, should be simplified. Appraisal methodologies may be differentiated according to the size or complexity of the project.

Finland (2006) The allocation of tasks provided by joint municipal boards reflects the hierarchy of spending shares in municipal budgets, allowing for great importance to health and to education services. A large proportion of public service delivery in Finland, whether primary and secondary education child care, health care, care for the elderly and culture (public libraries), is the responsibility of municipalities.

Basic services are often delivered by several services acting together ("joint municipal boards") and that co-operation is encouraged. There are 240 joint municipal boards, financed by member municipalities, representing about $20 \%$ of total municipal expenditure.

Many provincial, regional and local actors share responsibility, which entails problem of co-ordination, with possible overlapping.

Finnish "re-organisation of decentralisation" process has two key objectives: the progressive emergence of a regional level to co-ordinate competitiveness policy and the reinforcement of networking between different actors.

Japan (2016) The 1988 Municipal Government Act (loi communale) provides a reference framework for the distribution of responsibilities across levels of government, making a distinction between mandatory responsibilities (including some which are shared with central government or delegated) and optional responsibilities

Japanese cities suffer from fragmented governance. Governance fragmentation undermines
- The allocation of responsibilities reflects permanent interaction between upper and regional levels, between targets and proposals. Determination of process negotiation of strategies, programmes and projects.

- $\quad$ State and the regions can be facilitated through the Regional Councils, with a clear delimitation of mutual responsibilities in defining and implementing regional development strategies.

- Encourage deeper inter-municipal co-operation by devising awards on the basis of economies achieved by a joint municipal board.

- Regional development mechanisms and governance could be usefully reviewed. Greater emphasis on the role of Regional Councils in regional development strategies could facilitate partnership (i.e. explore how contractual and partnership approaches between the State and the regions can be facilitated through the Regional Councils, with a clear delimitation of mutual responsibilities in defining and implementing regional development strategies).

- Japan has still many small and struggling local governments. The merger incentives could have been stronger. The cities outside the metropolitan area must learn to work together. The evidence suggests that the performance of cities outside the "big three" would benefit from reinforced efforts to link nearby cities together, to sustain agglomeration benefits and targets and definition of strategies require the participation of all actors, in a 


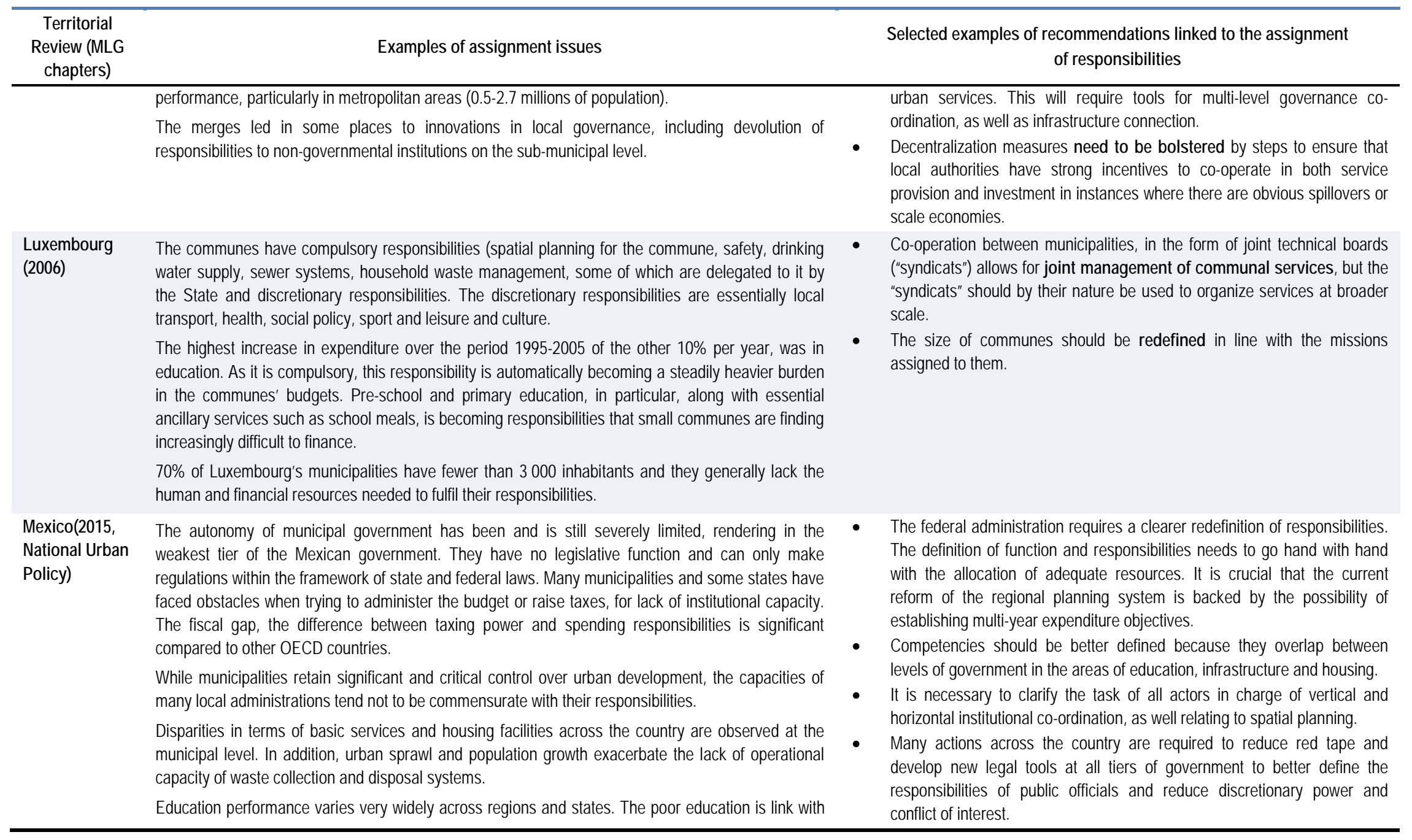




\begin{tabular}{|c|c|c|}
\hline $\begin{array}{c}\text { Territorial } \\
\text { Review (MLG } \\
\text { chapters) }\end{array}$ & Examples of assignment issues & $\begin{array}{l}\text { Selected examples of recommendations linked to the assignment } \\
\text { of responsibilities }\end{array}$ \\
\hline & $\begin{array}{l}\text { high disparities between regions and provided services. } \\
\text { In many cases, the responsibilities to develop basic services, like water, have been transferred from } \\
\text { public authorities to private housing developers. } \\
\text { Housing is but one of the many policy domains in which by law all three levels of government have } \\
\text { substantial - and at times overlapping - responsibilities. } \\
\text { Road construction and maintenance are split between the three levels, with the construction mainly } \\
\text { executed by federal and state governments, and maintenance mainly carried out by the state or } \\
\text { municipalities. } \\
\text { Parks and public transport are split with all levels of government providing services that correspond to } \\
\text { their geographic area, with public transport only rarely being managed by municipalities. }\end{array}$ & $\begin{array}{l}\text { - Assignment of responsibilities to various local governments could be } \\
\text { asymmetric based on population size, rural/urban classification and fiscal } \\
\text { capacity criteria. Thus, large cities may have responsibilities for some } \\
\text { services which are provided directly by the centre in other cities. }\end{array}$ \\
\hline $\begin{array}{l}\text { Netherlands } \\
\text { (2014) }\end{array}$ & $\begin{array}{l}\text { The Dutch subnational government system is unbalanced, between strong municipalities and weak } \\
\text { regional level. } \\
\text { The Dutch decentralisation reform aims to reallocate competences between the different levels of } \\
\text { government, in particular by re-enforcing provincial and municipal responsibilities and by establishing } \\
\text { simpler and clearer division of responsibilities between the different public actors, avoiding the } \\
\text { overlapping of functions. } \\
\text { The increasing number of municipal responsibilities has prompted discussions on amalgamating and } \\
\text { ensuring greater co-operation between municipalities in order to increase their capacity to deliver } \\
\text { these policies. The decentralisation reform has reignited the debate on the right size for } \\
\text { municipalities, and has become the main driver of the territorial reorganisation. Municipalities, } \\
\text { especially the smaller ones, will face major challenges performing their new mandatory social } \\
\text { functions adequately. Small municipalities may not have the capacity to deal with these new } \\
\text { responsibilities, in particular the managerial, administrative and financial capacities. } \\
\text { Provinces are in charge of administrative and financial supervision of municipalities and play a key } \\
\text { role in vertical co-ordination, bringing together a network of formal and informal stakeholders from } \\
\text { different levels of government. } \\
\text { Provinces are involved in setting long-term strategies in economic policy and transport and act as } \\
\text { intermediaries between the central government and municipalities to implement national priorities.? }\end{array}$ & $\begin{array}{l}\text { - In the context of decentralisation, the government should take into account } \\
\text { a medium and long time horizon for its implementation, provide assistance } \\
\text { and training to municipalities in coping with the new decentralised functions } \\
\text { and ensure the active involvement of citizens and other local stakeholders. } \\
\text { - As the central government has decided to abolish the eight city-regions } \\
\text { provinces should take back most of their competences, in particular in } \\
\text { spatial planning, transport, economic affairs and housing. The provinces' } \\
\text { role should also be strengthened in the field of spatial environment, traffic, } \\
\text { regional economy, the natural environment as well as culture. } \\
\text { - Territorial fragmentation at the province level can jeopardize the } \\
\text { implementation of major investment projects while they are vested, in the } \\
\text { same time, with larger responsibilities in this field. The provinces could } \\
\text { share or delegate some of their responsibilities to inter-municipal co- } \\
\text { operation structures through co-operative agreements. } \\
\text { Rescaling provinces and municipalities through mergers or co-operation } \\
\text { would improve their performance in the more decentralised context. For } \\
\text { provinces, further enhancing their strategic role in regional development } \\
\text { and co-ordination will also improve their competitiveness. }\end{array}$ \\
\hline Norway (2006) & There is a difference in spending between counties. The counties in the north of Norway spend & - Regional reforms cannot be efficiently carried out without a clear allocation \\
\hline
\end{tabular}




\begin{tabular}{|c|c|c|}
\hline $\begin{array}{l}\text { Territorial } \\
\text { Review (MLG } \\
\text { chapters) }\end{array}$ & Examples of assignment issues & $\begin{array}{l}\text { Selected examples of recommendations linked to the assignment } \\
\text { of responsibilities }\end{array}$ \\
\hline & 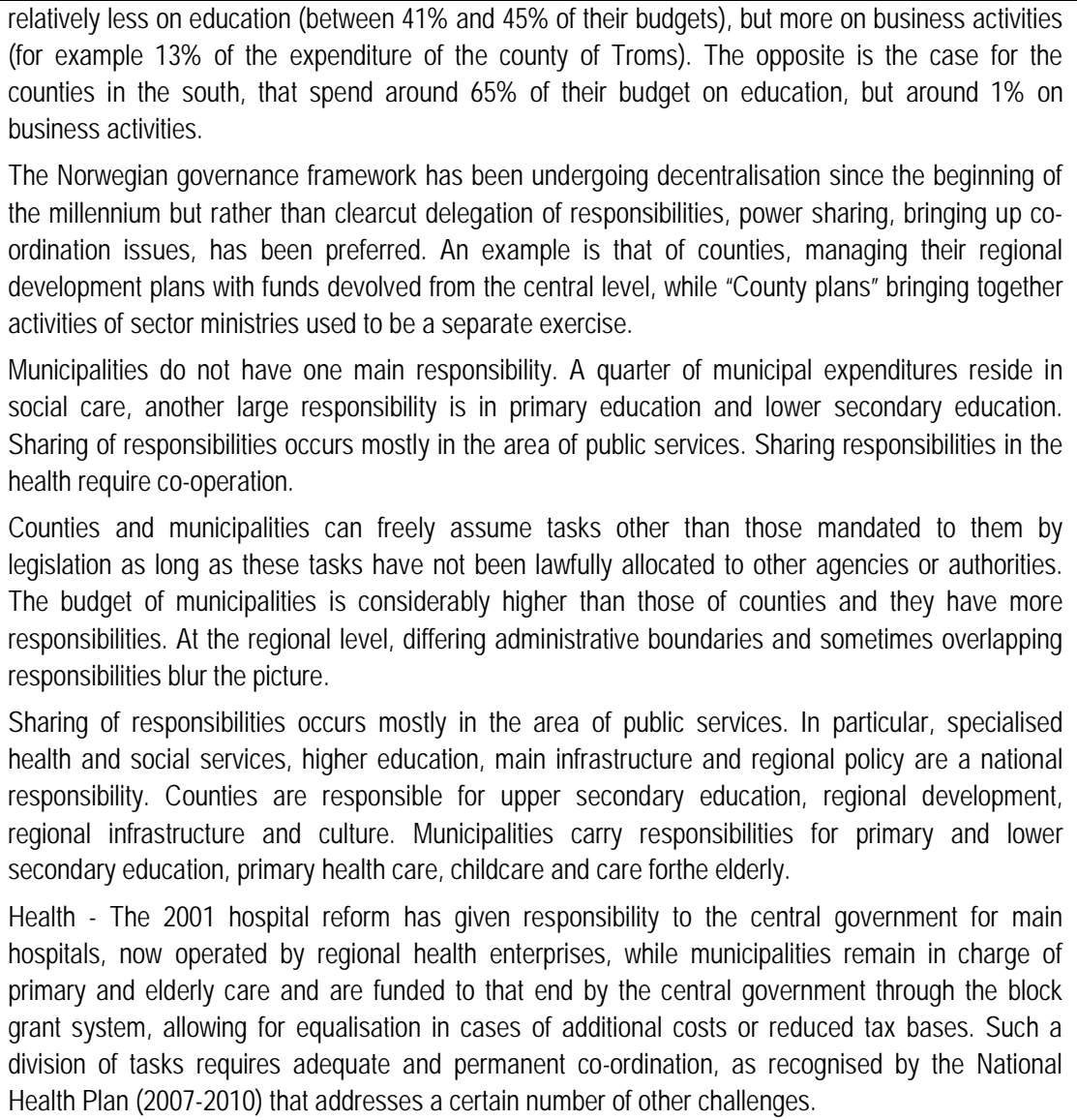 & $\begin{array}{l}\text { of responsibilities and resources. } \\
\text { - Possible new regional-level tasks include elements of regional spatial } \\
\text { planning; the transfer of certain county governor tasks to the county; } 10 \\
\text { more transport infrastructure responsibilities (for instance certain national } \\
\text { roads); more cultural tasks; enhanced R\&D responsibilities (including basic } \\
\text { funding of regional research institutes); involvement in the ownership of } \\
\text { Innovation Norway; and perhaps also new regional innovation corporations. } \\
\text { - When decentralising new responsibilities to counties, ensure that no } \\
\text { unfunded mandates are given, by clear transfer of corresponding } \\
\text { resources. } \\
\text { Clearly associate citizens and associations in the reform process by } \\
\text { systematic consultation and dissemination of information on the objectives } \\
\text { of the reform to counter apparent lack of interest in regional developments, } \\
\text { reflected by voter turnout which is lowest at the regional level. }\end{array}$ \\
\hline Poland (2008) & It is difficult for voivoships to play a strategic role in regional development, as they lack sufficient & - The distribution of competencies between regions, districts and \\
\hline
\end{tabular}




\begin{tabular}{|c|c|c|}
\hline $\begin{array}{l}\text { Territorial } \\
\text { Review (MLG } \\
\text { chapters) }\end{array}$ & Examples of assignment issues & $\begin{array}{l}\text { Selected examples of recommendations linked to the assignment } \\
\text { of responsibilities }\end{array}$ \\
\hline & $\begin{array}{l}\text { resources, flexibility in budget management, political visibility and enforcement power for spatial } \\
\text { planning. } \\
\text { The role of the powiats is increasingly questioned, as many of their functions could be moved either } \\
\text { to the voivodship or the municipality level. This could improve the efficiency of the decentralised } \\
\text { framework. } \\
\text { The current lack of co-operation across municipalities (gminas) makes it difficult to reap economies of } \\
\text { scale in terms of public service delivery and appropriate place-based competitiveness policies. } \\
\text { There are overlaps both across local governments and with state agencies/voivod offices in particular } \\
\text { for rural development, transport, health and employment policy. } \\
\text { (i) For rural development, regional local governments retain some responsibilities while rural } \\
\text { agencies, not dependent on the regional government, are in charge of implementing EU funding } \\
\text { linked to rural development: this constitutes a dual framework at the regional level for rural } \\
\text { development issues. } \\
\text { (ii) This is also the case for roads, as road maintenance formally is the responsibility of local } \\
\text { governments and various tiers of the state administration at the regional office and voivodship levels. } \\
\text { Given the large investments in road infrastructure that are currently planned in Poland and the high } \\
\text { operating costs that will result from them; clarification of the different responsibilities is needed. } \\
\text { (iii) Besides, there is an artificial division in social care/health between municipal level, poviat and } \\
\text { regional level. } \\
\text { (iv) Accountability remains unclear concerning employment policy. Although } 16 \text { regional labour offices } \\
\text { have been created, regions (marshal offices) have also taken some responsibilities in the fields of } \\
\text { scholarships and life-long training. In addition, poviats retain some responsibilities in labour market } \\
\text { policy, through the poviat labour offices. This results in a lack of coherence across the various } \\
\text { responsibilities on labour market policy at the local level, which may affect its efficiency. For example, } \\
\text { there is a critical lack of data on labour mobility at the local level, as no agency is officially in charge } \\
\text { of collecting these data. }\end{array}$ & $\begin{array}{l}\text { municipalities requires further clarification, in particular for education, health } \\
\text { and labour market policies, and additional revenues for gminas and regions } \\
\text { need to be secured. It could be envisaged to increase the shared taxes that } \\
\text { go to regions to enhance fiscal capacity of voivodships and the property tax } \\
\text { could be gradually expanded to increase revenues of gminas. } \\
\text { Increasing the strategic role of regions by increasing the political legitimacy } \\
\text { of regions and their capacity to arbitrate. } \\
\text { Poland needs to think about longer-term options for better matching } \\
\text { competencies and resources in some areas, especially when Polish regions } \\
\text { no longer benefit from the same level of external funding, and for further } \\
\text { increasing the strategic role of regions. } \\
\text { An integrated spatial planning approach is particularly urgent for the large } \\
\text { urban areas that drive Polish growth and face problems relating to housing, } \\
\text { public transport and the environment (including water and waste } \\
\text { management). } \\
\text { Co-operation by gminas, particularly at the metropolitan level, needs to be } \\
\text { promoted through specific incentives and an integrated approach to spatial } \\
\text { planning to improve public service delivery and to implement long-term } \\
\text { competitiveness strategies. Fiscal incentives could give large urban areas } \\
\text { flexible institutional tools for co-operating at the functional scale. } \\
\text { There is still a need for more effective regional leadership and clear } \\
\text { allocation of responsibilities and budgets among subnational authorities. } \\
\text { Flexibility into the implementation of regional development policy would } \\
\text { gain from a better match between responsibilities and resources }\end{array}$ \\
\hline Peru (2016) & $\begin{array}{l}\text { Regions have a role in the implementation of regional infrastructure and economic development } \\
\text { initiatives. However, regional governments do not endorse or monitor planning frameworks at a } \\
\text { provincial level, and lack the financial resources that would provide incentives for collaboration. The } \\
\text { national government also allocates and distributes resources directly to provinces and municipalities, }\end{array}$ & $\begin{array}{l}\text { - Establish a clearer definition of responsibilities across the levels of } \\
\text { government and a focus on partnerships to deliver better policy outcomes. } \\
\text { This includes clarifying exclusive competencies, and a clearer definition of } \\
\text { respective roles in the shared ones. Not all responsibilities can be clearly }\end{array}$ \\
\hline
\end{tabular}




\begin{tabular}{|c|c|c|}
\hline $\begin{array}{c}\text { Territorial } \\
\text { Review (MLG } \\
\text { chapters) }\end{array}$ & Examples of assignment issues & $\begin{array}{l}\text { Selected examples of recommendations linked to the assignment } \\
\text { of responsibilities }\end{array}$ \\
\hline & $\begin{array}{l}\text { which bypass the regional level. } \\
\text { Competences and responsibilities are not clearly defined between the levels of government. Within } \\
\text { the decentralisation framework, there are several overlaps in the competencies as well as limited } \\
\text { definition of the particular responsibilities assigned to each level of government. } \\
\text { There is a misalignment between responsibilities allocated to subnational governments and the } \\
\text { resources and capabilities available to them, which generates a systemic problem in relation to lack } \\
\text { of accountability for outcomes. The decentralisation process was too quick to transfers } \\
\text { responsibilities to subnational governments that didn't necessarily have the human and institutional } \\
\text { capacity to take them. } \\
\text { The ill-defined responsibilities were transferred simultaneously to all regions independently of their } \\
\text { capacities. The organic laws of the executive, regional and local governments respectively provide } \\
\text { more detail on the organisation and competences of the latter. These laws show that there is very } \\
\text { strong overlap between the missions and competencies across all levels of government. }\end{array}$ & $\begin{array}{l}\text { defined and an effective system of multilevel governance will also depend } \\
\text { upon stronger co-ordinating mechanisms, and the development of skills } \\
\text { and capabilities within subnational governments. } \\
\text { Peru should also explore using efficient multilevel governance, to put in } \\
\text { place asymmetric decentralisation, particularly for metropolitan areas. This } \\
\text { approach will allow for the flexibility to match responsibilities with resources } \\
\text { and capabilities, and ensure that policies are better matched to the local } \\
\text { needs and circumstances of cities and regions. }\end{array}$ \\
\hline Portugal (2008) & $\begin{array}{l}\text { Municipalities have only minor secondary rule making powers, but play a very important role in } \\
\text { licensing, as well as supervising and enforcing national regulations. Municipalities produce secondary } \\
\text { regulations to implement national rules in their territory with respect to urban and rural spatial } \\
\text { planning, transport, rural and urban equipment, energy, communications, education, health, housing, } \\
\text { social affairs, and environment. Such regulation is exclusively under their competence. } \\
\text { Portuguese municipalities are relatively large in terms of average population size compared with other } \\
\text { OECD countries and mayors usually enjoy strong political clout. } \\
\text { The responsibilities of the CCDR are complex and demanding, including regional spatial planning, } \\
\text { environmental issues, regional development, and support to local governments. }\end{array}$ & $\begin{array}{l}\text { - Reinforce the commitment of key regional actors (i.e. municipalities, } \\
\text { universities, business actors) in the implementation of regional strategies. } \\
\text { - Encourage functional collaboration based on potential synergies and } \\
\text { common development projects, notably by fostering more flexible inter- } \\
\text { municipal collaboration (not necessarily constrained at the NUTS } 2 \text { or } 3 \\
\text { level). } \\
\text { - Enhance efficient and responsible multi-level governance by promoting a } \\
\text { process of continuous learning at the subnational level through } \\
\text { monitoring and evaluation mechanisms i.e. using indicator system as a tool } \\
\text { can contribute to enhancing the efficiency and effectiveness of sub-central } \\
\text { service delivery by sharing information across levels of government and by } \\
\text { increasing the likelihood of achieving national goals for public services } \\
\text { delivered at the subnational level. } \\
\text { - Clarify the role of the CCDR as promoters of policy coherence and } \\
\text { facilitators of collaboration }\end{array}$ \\
\hline Slovenia (2011) & Municipalities are critical partners in regional economic development. Their number, seize, financing & - The division of responsibilities between national and local governments in \\
\hline
\end{tabular}




\begin{tabular}{|c|c|c|}
\hline $\begin{array}{c}\text { Territorial } \\
\text { Review (MLG } \\
\text { chapters) }\end{array}$ & Examples of assignment issues & $\begin{array}{l}\text { Selected examples of recommendations linked to the assignment } \\
\text { of responsibilities }\end{array}$ \\
\hline & $\begin{array}{l}\text { and functioning have implications for their ability to act as effective partners. Municipal road projects } \\
\text { tend to dominate within regional development programmes. } \\
\text { Highly fragmented municipal structure and the number of municipalities raises co-ordination and } \\
\text { governance challenges for regional development and public service delivery i.e. many municipalities } \\
\text { are too small to provide some public services efficiently. Slovenia appears to lack effective regional } \\
\text { co-ordination hubs that bring together issues and actors across sectors to achieve shared objectives. } \\
\text { Most municipalities do not have the capacity to conduct strategic planning or absorb EU funds in the } \\
\text { given timeframe. A large number of actors i.e. local development agencies, regional councils operate } \\
\text { in relatively small regions. This suggests the possibility of overlapping spheres of activity and/or an } \\
\text { inefficient fragmentation of tasks. } \\
\text { The involvement of municipalities in provision of key services, though very wide-ranging, is } \\
\text { sometimes limited in scope: in many instances they share responsibility (and financing) with the state } \\
\text { i.e. in education municipalities have exclusive control over preschool education only and shared } \\
\text { competences for primary education. }\end{array}$ & $\begin{array}{l}\text { early childhood and care could be better balanced. } \\
\text { - Further information and indicators should be developed at the national } \\
\text { government level about regional economies and municipal performance. } \\
\text { Both horizontal and vertical collaboration need to be strengthened in order } \\
\text { to avoid the proliferation of small-scale transport projects with little long- } \\
\text { term impact on regional economic growth. }\end{array}$ \\
\hline Sweden (2010) & $\begin{array}{l}\text { The main responsibility for health care lies with the } 20 \text { County councils (they spend more than } 80 \% \text { of } \\
\text { their budget) which own and run most hospitals and are responsible for the delivery of primary and } \\
\text { hospital care, including public health and preventive care. } \\
\text { County Councils are little involved in regional development, economic development or spatial } \\
\text { planning ( } 3 \% \text { of counties' expenditures). } \\
\text { The municipalities are deeply involved in the elaboration of the regional development programme } \\
\text { (infrastructure, planning, etc.). They have "municipal planning monopoly" i.e. they have primary } \\
\text { responsibility for the use of land and water within their jurisdiction. They must comply with the legal } \\
\text { framework and policy objectives set by the national government in a series of comprehensive plans. } \\
\text { Municipalities within county councils may together design regional spatial plans, but these are not } \\
\text { binding. } \\
\text { Over } 70 \% \text { of the services provided by municipalities depend on the size and age structure of the } \\
\text { population. Elderly care and care of the are important tasks of municipalities and account for almost } \\
30 \% \text { of local government's budget. }\end{array}$ & $\begin{array}{l}\text { - Counties are too small to cope with the complexity of health care provision } \\
\text { and their number should be reduced. } \\
\text { Sweden needs to enhance the room of manoeuvre for regional actors to } \\
\text { develop growth strategies that build on local competitive advantages. } \\
\text { Improved regional strategies require greater devolution of regional } \\
\text { development competencies to county councils, enhanced co-ordination } \\
\text { among the different types of regional programmes and improved co- } \\
\text { ordination of structural policies at the county level. }\end{array}$ \\
\hline Sweden & Sweden's multi-level governance structure, characterised by an "hourglass" shape - with strong & - Reconsider competence attribution at the subnational level, including \\
\hline
\end{tabular}




\begin{tabular}{|c|c|}
\hline $\begin{array}{l}\text { Territorial } \\
\text { Review (MLG } \\
\text { chapters) }\end{array}$ & Examples of assignment issues \\
\hline \multirow[t]{3}{*}{$\begin{array}{l}\text { (Monitoring } \\
\text { Review, 2017) }\end{array}$} & $\begin{array}{l}\text { upper (central) and lower (municipal) tiers, and a weaker middle (county) tier - appears to be } \\
\text { rounding out, as more County Councils gain regional development responsibilities. This is in keeping } \\
\text { with the } 2010 \text { OECD recommendation to encourage greater devolution of regional development } \\
\text { competences to County Councils. }\end{array}$ \\
\hline & $\begin{array}{l}\text { However, care should be taken that these important adjustments do not jeopardise Sweden's existing } \\
\text { asymmetrical and innovative approach to decentralisation, which to date has successfully permitted it } \\
\text { to adjust governance structures and competences according to territorial capacity, thus taking a } \\
\text { highly context dependent approach to regional governance and development rather than a one-size- } \\
\text { fits-all approach. }\end{array}$ \\
\hline & $\begin{array}{l}\text { Sweden is strengthening its dialogue-based approach to multi-level governance and improving its } \\
\text { capacity to co-ordinate the interests of a diverse set of actors in the political and civil service spheres. } \\
\text { The effort is supported by the Forum for Sustainable Regional Growth and Attractiveness. Improved } \\
\text { co-ordination among counties and central agencies that intervene at the regional level, however, } \\
\text { seems harder to accomplish. Subnational finance is another area where implementation of the OECD } \\
2010 \text { recommendations has been somewhat less successful. }\end{array}$ \\
\hline
\end{tabular}

\section{Selected examples of recommendations linked to the assignment} of responsibilities

through informal discussions to better understand the future resource
needs of new counties; to provide regions with greater autonomy in regional development, including with competences in the strategic planning of regional policy and in infrastructure investment; and to adjust the subnational governance structure, particularly with respect to County Administrative Boards, Regional Co-ordination Bodies, and central government agencies, consider a potential streamlining of agencies with regional activity.

- Providing county councils with regional development responsibilities; and continue asymmetrical approach for other responsibilities (e.g. employment/labour market; land-use/spatial planning)

- Improving co-ordination and coherence among central agencies that intervene at the regional level, and between these agencies and county authorities

- Ensuring that the territorial and operational logic of agencies better aligns horizontally (among each other) and vertically (notably with county boundaries).

- Continue adjustments to the grant system, including by:

- Improving its transparency and simplicity with adjustments to the income and cost equalisation models, as well as re-evaluating the effectiveness of the structural grant model.

- Restricting earmarked grants to those cases with demonstrated positive externalities, otherwise favour general grants

- Implement the regional reform and further merge counties, taking a systemic approach to the reform (beyond boundaries)

- Rely on functional labour markets to determine new county boundaries.

- Identifying and intervening in supra-cantonal functional areas should be facilitated by strengthening incentives for inter-cantonal co-ordination.

Switzerland The Swiss federal system guarantees substantial autonomy to the cantonal and local levels. Cantons play a large role in policy making andimplementation in Switzerland, including in regional economic policies. Many cantons make regional development plans that form the strategic framework for economic development in the canton. In addition they make implementation programmes for the New

- There is a lack of detailed and harmonised information on projects NRP at project level is needed to ensure a strategic monitoring of the 


\begin{tabular}{|c|c|c|}
\hline $\begin{array}{l}\text { Territorial } \\
\text { Review (MLG } \\
\text { chapters) }\end{array}$ & Examples of assignment issues & $\begin{array}{l}\text { Selected examples of recommendations linked to the assignment } \\
\text { of responsibilities }\end{array}$ \\
\hline & $\begin{array}{l}\text { development. } \\
\text { In } 2003 \text { were } 733 \text { inter-cantonal concordats among } 26 \text { cantons. They tend to focus on fields where } \\
\text { co-operation is pragmatic e.g. health services, maintenance of inter-cantonal roads. They also focus } \\
\text { on education, science and culture. There is a positive effect in the area of infrastructure, environment, } \\
\text { traffic and a negative effect in the area of finances/taxes. }\end{array}$ & $\begin{array}{l}\text { programme. } \\
\text { The monitoring and evaluation system needs to be strengthened in a } \\
\text { way that does not inflate federal control at the expense of cantonal } \\
\text { autonomy but allows for more strategic guidance. }\end{array}$ \\
\hline Ukraine (2013) & $\begin{array}{l}\text { Ukraine's main problem is the lack of a well-defined administrative structure with clear centres of } \\
\text { responsibility. In turn it contributes to a lack of transparency and predictability at all levels of } \\
\text { government. As a result, the subnational level is not prepared to take responsibility for most local } \\
\text { public services. } \\
\text { The allocation of transfers to subnational governments is not transparent. The lack of transparency in } \\
\text { the allocation of transfers generates uncertainty in the lower levels of government, hindering the } \\
\text { possibility to make medium-/long plans. At the lowest levels, very small elected authorities lack the } \\
\text { budget, expertise and scale needed for effective service provision. } \\
\text { The central allocation of resources to functions is based on historical data and input indicators. It is } \\
\text { the central government which decides what type of policies and services subnational tiers provide, } \\
\text { based on past experiences, often with insufficient knowledge of the actual needs of the population. } \\
\text { This mechanism produces inefficient use of resources. } \\
\text { Both health care and education lack a comprehensive assessment of the quality of the service, as } \\
\text { well an acceptable measurement system for performance and quality to guide health care and } \\
\text { education policy and reforms. } \\
\text { Measures should be put in place to gather information about the actual effects of policies on the } \\
\text { quality of such services. This information is essential to make the service more respondent to the } \\
\text { needs of the population, thus using the resources in a more efficient way. } \\
\text { Inter-regional and inter-municipal co-operation is also weak. There are practically no horizontal } \\
\text { relations among regions. Connections among cities would appear to be somewhat stronger but are } \\
\text { also quite limited, and co-operation among cities on specific development priorities is still very weak. }\end{array}$ & $\begin{array}{l}\text { - A territorial reform should be implemented prior to any decentralisation of } \\
\text { functions to lower levels of government; such a reform should facilitate } \\
\text { municipal mergers and the further development of new forms of inter- } \\
\text { municipal co-operation; simplify the legal procedures involved in } \\
\text { transferring competences to joint bodies or companies; and provide } \\
\text { additional financial incentives to jurisdictions that implement new types of } \\
\text { co-operative relationships. } \\
\text { - Horizontal co-operation between municipalities should be facilitated, } \\
\text { providing platforms for discussions where to exchange information and } \\
\text { experiences on the process of amalgamation. This process should be } \\
\text { guided through incentives from the central government but the decision } \\
\text { should be at the local level. } \\
\text { It is important to make co-operation among local governments easier } \\
\text { and more attractive i.e. richer and larger settlements can provide services } \\
\text { that are unfordable for others. } \\
\text { Resources allocated for the provision of local public services should be } \\
\text { based on the needs of the population in each area, not input indicators. } \\
\text { It is important to revise the formula for the allocation of transfers to } \\
\text { subnational tiers of government in order to make it simpler and less } \\
\text { discretionary. }\end{array}$ \\
\hline
\end{tabular}

